\begin{tabular}{|c|l|}
\hline Title & U pper mantle structure of marginal seas and subduction zones in northeastern Eurasia from Ray leigh wave tomography \\
\hline Author(s) & Bourova, E.; Y oshizawa, K.; Y omogida, K. \\
\hline Citation & $\begin{array}{l}\text { Physics of the Earth and Planetary Interiors, 183(1-2), 20-32 } \\
\text { https://doi.org/10.1016/.pepi.2010.06.007 }\end{array}$ \\
\hline Issue Date & 2010-11 \\
\hline Doc URL & http://hdl.handle.net/2115/44907 \\
\hline Type & article (author version) \\
\hline File Information & PEPI183-1-2_20-32.pdf \\
\hline
\end{tabular}

Instructions for use 


\title{
Upper mantle structure of marginal seas and subduction zones in Northeastern Eurasia from Rayleigh wave tomography
}

\author{
E. Bourova ${ }^{\mathrm{a}, \mathrm{b}, *}, \mathrm{~K}$. Yoshizawa ${ }^{\mathrm{a}, \mathrm{c}}, \mathrm{K}$. Yomogida ${ }^{\mathrm{a}}$ \\ ${ }^{a}$ Earth and Planetary Dynamics, Faculty of Science, Hokkaido University, Sapporo 060-0810, \\ Japan \\ ${ }^{b}$ Laboratoire de Geophysique Interne et Tectonophysique, 1381 rue de la Piscine, 38400 Saint \\ Martin d'Heres, France \\ ${ }^{c}$ Lamont-Doherty Earth Observatory, Columbia University, Palisades, NY 10964, USA
}

\begin{abstract}
The upper mantle structure of marginal seas (the Seas of Japan and Okhotsk) and subduction zones in northeastern Eurasia is investigated, using the threestage multimode surface wave tomography incorporating finite-frequency effects. Broadband waveform data from 305 events with magnitude greater than 5.5 from 1990 to 2005 recorded at 25 stations of the IRIS network in northeastern Eurasia and Japan and at 8 stations of the broadband seismic network in Far Eastern Russia from 2005 to 2008 are employed in our analysis. The dispersion curves of the fundamental mode and first two higher modes of Rayleigh waves are simultaneously inverted for the shear-wave velocity structure of the region. The off-great circle propagation due to strong heterogeneities in the region is also taken into account in the construction of intermediary phase velocity models for each mode as a function of frequency. The obtained 3D S-wave velocity model is well re-
\end{abstract}

\footnotetext{
*Corresponding author

Email address: katia.bourova@obs.ujf-grenoble.fr(E. Bourova)
} 
solved down to $200 \mathrm{~km}$ depth. Checkerboard tests show the average horizontal resolution of 5 degrees in the study region. The subducting Pacific plate is clearly imaged as a high velocity anomaly up to 6 percents. The mantle wedge above the Pacific plate is associated with low velocity anomalies. The absolute minimum $\mathrm{S}$ wave velocity in the mantle wedge is $4 \mathrm{~km} / \mathrm{s}$ in the Sea of Okhotsk in the depth range from 80 to $160 \mathrm{~km}$, probably indicating the presence of partial melt. The anomalous spot with conspicuous low velocity in the southern end of the Sea of Okhotsk may indicate the existence of hot upwelling flow in the mantle. A high velocity anomaly subparallel to the present subduction zone is found in the northwestern Sea of Okhotsk in the depth range from 100 to $200 \mathrm{~km}$. The position of this anomaly correlates well with the high velocity anomaly found in the P-wave tomography of Gorbatov et al. (2000), which may be interpreted as a relict of the Okhotsk plate subducted in the past. We also attempted a mapping of azimuthal anisotropy in this region. The fast phase velocity directions near the Pacific plate are observed subparallel to the Kuril and Japan Trenches at all the periods, indicating a strong effect of the subducting Pacific plate on the mantle flow, while the anisotropy appears to be weak in tectonically inactive marginal seas.

Keywords: Rayleigh waves, S wave velocity, upper mantle structure, the Sea of Japan, the Sea of Okhotsk.

\section{Introduction}

The Seas of Japan and Okhotsk are marginal seas in northeastern Eurasia, and their associated subduction zones are characterized by complex tectonic structure and geologic history. Located at junctions of six major plates (Bird, 2003), 5 the northeastern Eurasian region confines several subduction zones, arc-arc junc- 
tions and back-arc basins (see Figure 1). In north-eastern Japan, the Pacific plate subducts beneath the Okhotsk plate at a rate of about $8-10 \mathrm{~cm} / \mathrm{year}$ to the westnorthwest (Hasegawa et al., 1994; Bird, 2003). This subduction process is related to high volcanic activities in this area. In south-western Japan, the Philippine Sea plate subducts to the northwest beneath the Amur plate at a rate of $4.5 \mathrm{~cm} / \mathrm{year}$ (Sugimura, 1972; Ando, 1975; Seno et al., 1993). The eastern end of the Philippine Sea plate subducts beneath the Okhotsk plate to the north. The Okhotsk plate is regarded as a plate independent of the major North-American plate (Seno et al., 1996). The Amur plate moves slowly with respect to the Eurasian plate (Zonenshain and Savostin, 1981; Wei and Seno, 1998), colliding with the Okhotsk plate (Seno, 1999).

Origin and tectonic evolution of the present marginal seas in this area are highly complex, and details of their tectonic history have not been well resolved due to the lack of extensive surveys in the seas. While the formation of the Japanese Islands is closely related to the opening of the Sea of Japan, their detail evolution is grossly estimated by some surveys of geomagnetic anomalies in the Sea of Japan as well as paleomagnetic studies of basement rocks in the islands (Taira, 2001). The information of the Sea of Okhotsk is further limited with a few geomagnetic surveys available (Verzhbitsky et al., 2006). Verzhbitsky and Kononov (2006) proposed an evolution model of the Sea of Okhotsk over the past $90 \mathrm{Ma}$.

The tectonics in the northeastern Eurasia region is governed primarily by the oceanic Pacific plate subducting beneath the Okhotsk and Philippine Sea plates along Kamchatka, Kuril, Japan and Izu-Bonin seismogenic zones. The seismicity beneath the Japan trench represents a deep seismic zone in the Pacific plate dip- 
ping at an angle of 30 degrees or more. Intermediate and deep earthquakes occur down to a depth of about $670 \mathrm{~km}$. The intermediate seismicity around $60-200 \mathrm{~km}$ depth is splitted into two planar groups, parallel to each other and 30-40 km apart, called a double seismic zone (Hasegawa et al., 1978, 1991; Zhao et al., 2009). The dip angle of the subducting slab beneath the Kuril trench is slightly higher than that of the Japan trench, ranging from $40^{\circ}$ to $55^{\circ}$ (Castle and Creager, 1998; Hasegawa et al., 1994; Katsumata et al., 2003).

Beneath the Kamchatka peninsula, the Pacific plate subducts westward at a rate of about $8 \mathrm{~cm} / \mathrm{year}$, according to NUVEL-1 (DeMets et al., 1990; DeMets, 1992). In the southern part of the Kamchatka, a Wadati-Benioff zone defines a downgoing slab to the maximum depth of $500 \mathrm{~km}$, dipping at an angle of about $55^{\circ}$. Near the Aleutian-Kamchatka corner, this depth shallows gradually to 300 $\mathrm{km}$ and the dip angle of a Wadati-Benioff zone decreases from $55^{\circ}$ to $35^{\circ}$ (Gorbatov et al., 1997; Park et al., 2002).

Investigation of the 3D mantle structure in this region should enable us to better understand its complex tectonic processes. In the last two decades, seismic tomography methods have been intensively applied to the mantle structure in northeastern Eurasia and Japan on global and regional scales. Many researchers used body wave tomography techniques to obtain images of the Pacific plate subducting beneath this region (van der Hilst et al., 1991, 1998; Widiyantoro et al., 1999; Gorbatov et al., 2000; Zhao, 2001, 2004; Miller et al., 2006; Huang and Zhao, 2006; Zhao, 2009). The Pacific plate has been imaged down to $660 \mathrm{~km}$ depth, where it stagnates near the mantle transition zone (Fukao et al., 2001). In addition, high resolution images of the mantle beneath the Japanese islands have been obtained by body wave tomography with a high velocity Pacific plate 
introduced into initial models (Hasegawa et al., 1991; Zhao et al., 1994; Mishra et al., 2003; Wang and Zhao, 2005; Shelly et al., 2006; Zhao et al., 2009). This technique allows us to map small-scale heterogeneities in the region successfully, although such results depend on the validity of the initial assumption. The obtained models show a sharp P-wave velocity contrast across the top of the Pacific slab, and small-scale low velocity anomalies are imaged beneath several active volcanoes.

On the other hand, the resolution of body wave tomography on both local and global scales is limited beneath the Seas of Japan and Okhotsk because of a non-uniform distribution of earthquakes and a lack of seismic stations there. The 3D upper mantle structure of this region may be better constrained by surface waves, but only a few studies with local-scale surface wave tomography have been ever performed (Li et al., 2001; Lebedev and Nolet, 2003; Takezoe et al., 2005). These studies covered only the Japanese islands and the Sea of Japan. Most of the Seas of Japan and Okhotsk have been investigated only as a part of large-scale surface wave tomography studies (van Heijst and Woodhouse, 1999; Ritzwoller and Levshin, 1998; Priestley et al., 2006).

In this study, we present a three-dimensional S-wave velocity model of the upper mantle beneath the Seas of Japan and Okhotsk and their neighbouring region in Northeastern Eurasia with Rayleigh waves. Subduction zones are known as a region of strong heterogeneities, resulting in large off-great circle propagations, for example, in the northwestern Pacific ocean (Isse et al., 2006). In such circumstances, velocity structures are not properly modelled by the conventional surface wave ray theory. We therefore use the method of multimode surface wave tomography of Yoshizawa and Kennett (2004), which allows us to take into account both 
ray bendings and finite-frequency effects. The vertical resolution is enhanced by the simultaneous use of the fundamental and first two higher modes of Rayleigh waves. We also analyze azimuthal variations of phase velocity as the first attempt to retrieve local-scale anisotropic characters in this region.

\section{Data and Method}

In this study, we used three-component broad-band seismograms of FARM (Fast Archive Recovery Method) data collected from the IRIS (Incorporated Research Institutions for Seismology) network in the Northestern Eurasian region $\left(30^{\circ} \mathrm{N}-75^{\circ} \mathrm{N}\right.$ latitude, $120^{\circ} \mathrm{E}-175^{\circ} \mathrm{E}$ longitude). The IRIS station distribution in this region is, however, too sparse to fully constrain the regional structure around the Seas of Japan and Okhotsk. As a part of Japanese Stagnant Slab Project for delineating stagnant slabs in the mantle transition zone beneath Northeastern Eurasia, a temporary seismic network with 8 broadband stations has been deployed in Far Eastern Russia since 2004 (Miyamachi et al., 2009). We included the data from this regional network to improve the horizontal resolution of our results and to better understand the dynamics processes occurring in the region.

We selected seismic events of magnitude greater than $5.5 \mathrm{Mw}$ from 1990 to 2005 for the IRIS data, and from September 2005 to December 2008 for the temporary Far-East Russian stations. We chose Rayleigh waveforms with good signal-to-noise ratio recorded in the vertical component of the seismograms. The used data set is composed of 33 stations and 305 events. The distributions of stations and events are shown in Figure 2. Locations and origin times of the earthquakes are taken from the IRIS catalogue. The centroid moment tensor solutions from the global CMT catalogue (Ekström et al., 2005) are used. All the data are 
initially corrected with an instrument response of each station.

The obtained waveforms are processed by the three-stage inversion technique proposed and developed by Kennett and Yoshizawa (2002) and Yoshizawa and Kennett (2004), which comprises the following three independent steps:

(1) We extract the dispersion information of each available source-station path from the observed waveform. The phase velocity dispersion curve is measured for the fundamental and first a few higher modes through waveform fitting.

(2) The dispersion information from all the paths is combined to produce multimode phase velocity maps as a function of frequency. Linear inversions are performed based on the assumption that the surface wave paths follow great-circles. Subsequently, 2-D phase velocity maps are updated by including ray traces and finite-frequency effects.

(3) We invert the local dispersion information at each location point for a local one-dimensional S-wave velocity profile. The final three-dimensional S wave velocity model is constructed from the set of the updated multimode phase velocity maps.

This approach offers the advantage of combining a variety of information such as multi-mode dispersion, off-great circle propagation and finite-frequency effects in a common framework.

\section{Path averaged multimode dispersion curves}

To retrieve the multimode dispersion information for each path in the first step of the three-stage inversion, we used the fully non-linear waveform inversion method of Yoshizawa and Kennett (2002a) based on the neighbourhood algorithm 
(NA) of Sambridge (1999). The NA is used as a global optimizer to find models with smaller misfit in a model parameter space. Filtered seismograms in different frequency ranges and their weighted envelopes are simultaneously minimized.

In this waveform inversion, a set of path averaged one-dimensional S-wave velocity models are generated through the non-linear waveform fitting with the NA for each event-station path. We calculated $3000 \mathrm{~S}$-wave velocity models for each path. The best fit model corresponding to the minimum of the misfit function is selected to estimate the multi-mode dispersion. The standard error is estimated as a standard deviation from the best 1000 models. Then, the reliability parameter defined by Yoshizawa and Kennett (2002a) is calculated for the best fit model, which quantifies the relative amplitudes of each mode excited at the source as well as the degree of fit between synthetic and observed waveforms.

As a reference model to initiate this model parameter search, we used PREM (Dziewonski and Anderson, 1981) or PREMC (a modified version of PREM to better represent the continental upper mantle), depending on a path whether it lies mostly on an oceanic or a continental region. The crustal structure is corrected beforehand using the 3SMAC model (Nataf and Ricard, 1996).

We restricted the analyzed period range to be longer than 30 seconds to avoid unwanted effects of mode branch coupling (Kennett, 1995). We only used the data from relatively far events with angular distances greater than 9 degrees (or about $1000 \mathrm{~km}$ ), so that the fundamental-mode Rayleigh waves are reasonably separated from their preceding body wave arrivals.

In order to check the quality of the measured dispersion curves, we applied a manual quality control for the IRIS-FARM data set according to several data selection criteria. First, we discard seismograms if the station is located in a nodal 
direction from the source for the radial amplitude of Rayleigh waves roughly less than a half of the maximum. Next, we perform the inversion with five different initial models, from "Model 1" to "Model 5", which includes S-wave velocity perturbations of -3 to $+3 \%$ from a reference model in the top $250 \mathrm{~km}$ with $1.5 \%$ increment. We only keep the data which provide stable waveform inversion results for all the models, and the resultant dispersion curves are checked visually to discard some outliers. The threshold values for the minimum reliability parameter is set to 4 for the fundamental mode and 1.5 for the first higher mode. If all the criteria mentioned above are acceptable, the data are selected for the second stage of the inversion scheme.

An example of the NA waveform inversion for IRIS-FARM data is illustrated in Figure 3 for an earthquake of magnitude $M w=6.1$ near the eastern coast of Honshu (Japan) on 3rd October 2000 recorded at the station HIA. Using "Model 3 " as the initial model in this example, we display the best-fit waveforms (Figure 3a), the best fit path averaged S-wave velocity model (Figure 3b), the multimode phase velocity dispersion curve (Figure 3c) and the reliability parameter (Figure $3 d)$.

For the data set from the network in Far East Russia, we used a new automated method developed by Yoshizawa and Ekström (2009). The quality of waveform fit and phase speed measurements are checked through several quantitative parameters with empirical threshold criteria, including an average radiation amplitude of each mode, a total misfit of multiple time windows, and a reliability parameter. The combination of these parameters enables us to select reliable dispersion measurements in a fully automatic manner.

We measured phase velocity dispersion curves from 30 to $150 \mathrm{~s}$ period for the 
fundamental mode, from 30 to $140 \mathrm{~s}$ for the first higher mode and from 30 to 120 $\mathrm{s}$ for the second. The number of the used paths depends on period and varies from 980 to 1099 with a total of 1129 different paths. The distribution of the selected paths is shown in Figure 4.

\section{Multimode phase velocity dispersion curves}

In the second stage, the dispersion curves obtained for various paths are used to reconstruct phase velocity maps of the region. Following Yoshizawa and Kennett (2004) we obtain two types of phase velocity models, called GC and Riz models, which are derived from different assumptions. First, we calculate perioddependent phase velocity maps, GC models, supposing that surface waves propagate along great circles. These models use the great circle approximation without any consideration of the off-great circle propagation and of the zone of influence. Phase velocity maps are calculated at periods from 30 to $150 \mathrm{~s}$ for the fundamental and first two higher modes of Rayleigh waves with a grid interval of 3.0 degrees. Figure 5a shows an example of the GC models for the fundamental mode of Rayleigh wave at period of $50 \mathrm{~s}$.

We then obtain an updated phase velocity maps, Riz models, using ray tracing in the reference heterogeneous models, GC models, derived from the great-circle approximation. In this updating process, we also consider finite frequency effects using an influence zone, in which surface waves are coherent in phase (Yoshizawa and Kennett, 2002b). To expand the phase velocity perturbation over the influence zone, we use a spherical B spline function (Lancaster and Salkauskas, 1986; Wang and Dahlen, 1995) defined at the center of a geographical cell as a basis function. The detailed inversion method for phase velocity models is described 
by Yoshizawa and Kennett (2002a). The Riz models (Figure 5b), improve results of the phase velocity mapping in a similar manner to previous studies (e.g. Isse et al., 2006).

The trade-off between the model norm and the resolution in model for this inversion is controlled by an arbitrary damping parameter $\lambda$. Figure 6 shows the trade-off curve for the Riz model of the fundamental mode at period of $100 \mathrm{~s}$, very similar to that for the corresponding GC model. As reasonable compromise between the misfit and the model norm, we chose the damping parameter $\lambda=$ 1.0 in this example. The highest variance reduction of 54\% is achieved for the fundamental mode at period of $50 \mathrm{~s}$ for the Riz model, and from $23 \%$ to $49 \%$, depending on period, for the first and second higher modes.

To estimate the horizontal resolution of the present inversion, we performed checkerboard tests at period of $50 \mathrm{~s}$ with anomalies of \pm 4.8 -percent amplitude for 4, 5, 6 and 8 degree cell sizes (Figure 7), considering the effects of off-great circle propagation and finite frequency of surface waves for both forward and inverse modellings. These tests show that the available path coverage provides us with good resolution beneath the Seas of Japan and Okhotsk for anomalies of 5 degrees and more, while small-scale anomalies of 4 degrees cannot be resolved sufficiently. To preserve the resolved features, we adopted a model with 3 degrees of distance between the grid points. Nevertheless, some small anomalies could be artefacts in such model due to the gridding. While using the 3 grid model, we avoid discussions on small-scale anomalies less than 5 degrees in the interpretation of our results. The influence of different grid sizes on our final S-wave velocity model is discussed in section 5.1.

Figures 8 shows the resulting phase velocity maps of fundamental-mode Rayleigh 
waves at periods of 50, 75, 100 and $150 \mathrm{~s}$ with grids of 3 degrees. A large-scale high velocity anomaly can be seen in all the maps along the Kuril and Japan trenches which corresponds to the subducting Pacific slab. Low velocity anomalies beneath the east of the Sea of Japan and the southeast of the Sea of Okhotsk are associated with the mantle wedge above the subducting slab where we would expect high temperature anomalies.

\section{Three-dimensional $\mathrm{S}$-wave velocity model}

\subsection{Inversion for S-velocity model}

In the final stage, the local dispersion curves are inverted into a one-dimensional $\mathrm{S}$ wave velocity model at each point of the region. The inverted one-dimensional models are then assembled into the final three-dimensional $\mathrm{S}$ wave velocity map. The relation of multimode phase dispersion and local one-dimensional structure can be represented by the following linearized relation (Takeuchi and Sato, 1972; Dahlen and Tromp, 1998):

$$
\frac{\delta c(\omega)}{c}=\int_{0}^{R}\left\{K_{\rho}(\omega, z) \frac{\delta \rho(z)}{\rho}+K_{\alpha}(\omega, z) \frac{\delta \alpha(z)}{\alpha}+K_{\beta}(\omega, z) \frac{\delta \beta(z)}{\beta}\right\} d z,
$$

where $\delta c$ is the perturbation of phase velocity in frequency or period; $\delta \rho, \delta \alpha$ and $\delta \beta$ are the perturbations of density, P-wave velocity and S-wave velocity as a function of depth, respectively; and $R$ is the maximum depth considered. The sensitivity kernels $K_{\rho}, K_{\alpha}$ and $K_{\beta}$ represent the partial derivatives of phase velocity with respect to each of the model parameters. Since the phase velocity of surface waves is mostly sensitive to S-wave velocity structure with only limited sensitivity to Pwave velocity and density perturbations (Nataf et al., 1986), we fix the density 
and $\mathrm{P}$ velocity structures to a reference model and invert only for S-wave velocity perturbations.

Both the fundamental mode and the first two higher modes of Rayleigh waves are inverted simultaneously by the iterative least squares inversion scheme of Tarantola and Valette (1982). The smoothness of the resulting one-dimensional model is represented by a priori model covariance with a Gaussian distribution (Cara and Lévêque, 1987; Nishimura and Forsyth, 1989). The degree of smoothness is parametrized by a correlation length $L$ and a standard deviation $\sigma$. We used $\sigma=0.1 \mathrm{~km} / \mathrm{s}$ and $L=20 \mathrm{~km}$ beneath the Moho. Above the Moho, the correlation length is chosen to be $L=5 \mathrm{~km}$ with the same $\sigma$ to allow more rapid velocity variations.

The one-dimensional models obtained by the above inversion generally depend on the adopted initial model. Since the average phase velocity measured in our study region is significantly lower than PREM, we used "PREM-3\%" as the initial model with 3 percents slower than PREM in the upper mantle. In addition, the initial model is adapted to have smooth variations across boundaries at 220, 400 and $670 \mathrm{~km}$ depth and its crustal part is corrected by the 3SMAC model (Nataf and Ricard, 1996), similar to the case of the first stage.

The resolution kernels with $\mathrm{S}$-wave velocity for a typical one-dimensional model are presented in Figure 9 for the location of $(35 \mathrm{~N}, 140 \mathrm{E})$. These profiles show comparatively good resolution down to the depth of $200 \mathrm{~km}$ where the structure is mainly constrained by the fundamental mode. The higher modes are less sensitive to S-wave velocity variations compared to the fundamental mode, so that the resolution is not satisfactory at the depth below $200 \mathrm{~km}$. Nevertheless, there is some sensitivity down to $250 \mathrm{~km}$ depth, mostly owing to the higher modes. 
Figure 10 displays four models of $\mathrm{S}$ wave velocity perturbations at $100 \mathrm{~km}$ depth obtained for different grid sizes: 2, 3, 4 and 5 degrees. The distribution of $\mathrm{S}$-wave velocity is plotted relative to the average $\mathrm{S}$-wave velocity at each depth. The 2 degree model contains some small-scale anomalous patches, which could be artefacts due to poor horizontal resolution. In contrast, the 5 degree model presents a reliable but much smoother solution of the inversion. In the subsequent discussion, we use the 3-degree model with a reasonably good resolution in the entire region.

\subsection{D model of the northeastern Eurasian region}

Horizontal depth slices of S wave velocity are presented for the final threedimensional model in the depth range from 50 to $200 \mathrm{~km}$ in Figure 11. The southwest part of the Japanese islands (30-35 degree latitude) is excluded from our result because the number of ray paths in this region is rather small (see Figure 4) and the model is less reliable. The overall S-velocity structure in this region is dominated by a high velocity anomaly associated with the subduction of the Pacific plate. The subducting Pacific plate shows conspicuous velocity contrast with the surrounding mantle up to $6 \%$ at depth shallower than $200 \mathrm{~km}$.

Beneath the Sea of Okhotsk, the depth slice at $50 \mathrm{~km}$ presents a relatively high velocity anomaly of $3 \%$ in the southern part of the Sea of Okhotsk. This anomaly correlates well with the position of the South Kuril Basin (or the South Okhotsk basin) underlain by oceanic lithosphere (see Figure 4 of Verzhbitsky et al., 2006). In contrast, there are no significant velocity anomalies in the northern part, which corresponds to Central Okhotsk massif with continental crust. The Kamtchatka Peninsula shows low velocity at depth of $50 \mathrm{~km}$, implying active tectonic activities of an island arc type with thick continental crust. The S-velocity 
maps at depth of 100-200 km display the presence of noticeable low velocity anomalies in the southeastern Sea of Okhotsk along the Kuril subduction zone. In this area, negative velocity perturbations reaches about $-10 \%$. We show three vertical cross sections of the 3D S-wave velocity model in Figure 12. The profiles are nearly perpendicular to each section of the subduction zone. Two of them are close to the profiles published in previous studies: AA' corresponding to the crosssections AA' of Lebedev and Nolet (2003), and the cross-section CC' comparable to DD' or EE' of Gorbatov et al. (2000).

The cross-sections AA', BB' and CC' show the S-wave velocity perturbations beneath the northern Japan and the Sea Okhotsk down to $250 \mathrm{~km}$ depth. The subducting Pacific plate is well resolved as a high velocity anomaly of approximately 6 percents. The limited lateral resolution of our data does not allow us to resolve the precise shape of the slab, resulting that the imaged slab appears more elongated and flatter than the actual plate.

In the central part of the cross-section BB', beneath the southern Sea of Okhotsk, we find a large low velocity anomaly. The absolute $\mathrm{S}$-wave velocities are as low as $4.0 \mathrm{~km} / \mathrm{s}$ at depth of $80-160 \mathrm{~km}$, indicating the presence of partial melt. The overall stress field in the Hokkaido region has been found anomalous, not consistent with the stress field predicted by the subductions of its surrounding major plates of Figure 1. The strong low velocity anomalous spot in the southern end of the Sea at depth of 80 to $160 \mathrm{~km}$ may support a hypothesis of hot upwelling flow in the mantle in the south of the Sea of Okhotsk, although there have been no direct observational evidences.

Another interesting feature is a high velocity anomaly in the north-western Sea of Okhotsk (in the left of cross sections BB' and CC') found between 100 and 
$250 \mathrm{~km}$ depth. The lateral size of the anomaly is at least $500 \mathrm{~km}$. The anomaly is extended in the NE-SW direction, subparallel to the present Pacific subduction zone. The $S$-wave velocity perturbation of this anomaly is approximately +6 percents, nearly the same as obtained for the Pacific slab. The position and amplitude of this high velocity anomaly seems to indicate an extinct subduction zone behind the Kuril trench.

A high velocity anomaly in P wave was imaged by Gorbatov et al. (2000), subparallel to the Pacific subduction zone in the northern part of the Sea of Okhotsk, between 200 and $660 \mathrm{~km}$ depth. They suggested that it may correspond to the relict of the subducted Okhotsk plate. The Okhotsk subduction zone was once active before $\sim 55 \mathrm{Ma}$. The cessation of the subduction process seems to be caused by the trapping of the Okhotsk plate after a jump in the subduction zone from the northern Asian margin to the Kuril-Kamchatka trench, which is estimated to have occurred in the period of 55-65 Ma (Parfenov and Natal'in, 1985; Kimura, 1994). Taking advantage of better resolution of the surface waves in the Sea of Okhotsk, we confirm the presence of the above high velocity anomaly beneath the northern part in the depth range of 100-200 km, consistent with the result of Gorbatov et al. (2000).

There are other anomalous parts in the 3-D S wave velocity model than those beneath the Sea of Okhotsk. The northern Sea of Japan (Japan Basin in Figure 1) is characterized by slightly high velocity anomaly shallower than $100 \mathrm{~km}$ and low in a deeper range, implying its lithosphere to be oceanic. The depth slice at $50 \mathrm{~km}$ in Figure 11 shows slightly high velocities in Japan Basin in comparison with the other parts of the Sea, which can be explained by the presence of different types of oceanic lithosphere within the Sea. However, we have only the limited azimuthal 
coverage of ray paths in this area (Figure 4), so that its horizontal resolution is as large as about 5 degrees (Figure 7). Therefore, we are not able to give decisive conclusions on small-scale variations of S-wave velocities in this region from the currecnt model. A more detailed structure in this region has recently been investigated by Yoshizawa et al. (2010) with higher resolution. They imply that its shallow structure is likely to be different from the standard oceanic lithosphere.

The S-wave velocity model includes several anomalous areas beneath the northeastern corner of the Eurasian continent although they are not highly reliable due to sparse path coverage and poor resolution in this part of our model. A low anomalous spot exists near the triple border of Russia, China and North Korea, particularly in a depth range from 100 to 150 km, as shown in Figure 11 and AA' of Figure 12. Lei and Zhao (2005) proposed a region of low velocity anomaly beneath the historically active Changbai (Baekdu) volcano with their P-wave travel time tomography. Lei and Zhao (2005) interpreted this low velocity anomaly as an intraplate volcano associated with the deep subduction of the Pacific slab. For details, please also refer to Zhao et al. (2009). Our low velocity anomaly may correspond to this proposed intraplate volcano although its location is slightly different, probably due to the poor resolution of the current model in this area.

A slow velocity anomaly is found in the depth below $150 \mathrm{~km}$ in the south of Hokkaido, but this location is close to an edge of our model space. Therefore, we are unable to dicuss the detailed local structure in this area.

\section{Azimuthal anisotropy around the Japanese islands}

Using path-specific phase velocities, we estimate dominant features of azimuthal anisotropy for the fundamental-mode Rayleigh wave, which would pro- 
vide us with useful information on the mantle dynamics beneath this region that cannot readily be inferred from the isotropic $\mathrm{S}$-wave velocity model. The azimuthal anisotropy of surface waves can be modelled by the following linear approximated formulation (Backus, 1965; Smith and Dahlen, 1973) under the assumption of weak anisotropy:

$$
c(\mathbf{r}, \psi)=c_{0}(\mathbf{r})+A_{1}(\mathbf{r}) \cos 2 \psi+A_{2}(\mathbf{r}) \sin 2 \psi+A_{3}(\mathbf{r}) \cos 4 \psi+A_{4}(\mathbf{r}) \sin 4 \psi,
$$

where $\mathbf{r}$ is the position vector on a sphere, $\psi$ is the direction of wave propagation, $c_{0}$ is the isotropic part of phase velocity, and $A_{i}$ are the anisotropic coefficients. As can be understood from equation (2), introducing the azimuthal anisotropy dramatically increases the number of parameters to be determined and the relatively uniform azimuthal distribution of ray paths is required. Figure 13 shows a checkerboard resolution test for azimuthal anisotropy at period of $50 \mathrm{~s}$ for 8 and 10-degree cellular patterns. This resolution test suggests that our data set is sufficient to retrieve large-scale patterns of azimuthal anisotropy. For simplicity, we use the great-circle approximation without any effect of finite frequency in the inversion for azimuthal anisotropy. The inversion is performed only for isotropic term $c_{0}$ and $2 \psi$ terms $\left(A_{1}\right.$ and $\left.A_{2}\right)$, and $4 \psi$ terms are not considered. We confirmed that the exclusion of $4 \psi$ terms does not affect the results of $2 \psi$ terms.

In this study, both the isotropic and anisotropic terms of phase speed perturbations are expanded in spherical B-spline functions as for the case of the isotropic inversion described in section 4 . We employ a grid interval of 4 degrees for expanding both isotropic and anisotropic terms, so that we are able to retrieve reliable and stable estimate of azimuthal variations of Rayleigh wave phase velocity in this region.

Figure 14 displays the obtained $2 \psi$ anisotropic terms plotted over the isotropic 
phase velocity map for periods of $45 \mathrm{~s}, 70 \mathrm{~s}$ and $100 \mathrm{~s}$, with each bar representing the direction of the fastest velocity at a given location. This figure shows that the fast phase velocity directions near the Pacific plate are subparallel to the Kuril and Japan Trenches at all the periods, indicating the influence of the subducting Pacific plate on the azimuthal anisotropy in this region. A similar pattern of seismic anisotropy has been observed in several major subduction systems from the observations of shear wave splitting, probably caused by significant trench parallel flow (Anderson et al., 2004; Nakajima and Hasegawa, 2004; Kneller and van Keken, 2007; Wang and Zhao, 2008, 2009).

In contrast, the azimuthal anisotropy is weak beneath the Seas of Okhotsk and Japan. The back-arc spreadings of these marginal seas ceased about $10 \mathrm{Ma}$, and currently inactive, implying no vigorous geodynamic activities at present.

\section{Conclusions}

The three-stage surface wave tomography was successfully applied to the IRIS-FARM data in the northeastern Eurasian region and the temporary broadband seismic network in Far Eastern Russia, including effects of off-great circle propagation and finite frequency. The fundamental and first two higher modes of Rayleigh waves in a period range from 30 to $150 \mathrm{~s}$ were inverted for a S-wave velocity model for each pair of source and station. The available data set allowed us to resolve the structure beneath the Japanese Islands and the Seas of Japan and Okhotsk down to $200 \mathrm{~km}$ depth with the average lateral resolution of 5 degrees.

Our final three-dimensional S-wave velocity model revealed a high velocity anomaly along the subduction zones, which is associated with the subducting Pacific plate. The velocity differences between the slabs and the surrounding mantle 
reaches 6 percents. The mantle wedge is imaged as a low velocity zone, adjacent to each part of the subducting plate. In the southern Sea of Okhotsk, S-wave velocity reaches $4 \mathrm{~km} / \mathrm{s}$ in the depth range of $80-160 \mathrm{~km}$. This low velocity anomaly can be interpreted as mantle wedge of thermal anomalies with possible partial melt in the upper mantle. Our result seems to support a hypothesis of hot upwelling flow in the mantle in this area.

A large-scale high velocity anomaly of at least $500 \mathrm{~km}$ wide is detected in the northwestern Sea of Okhotsk, that is, in the north of the subducting slab and the above mantle wedge. This high velocity anomaly of 6 percent is extended subparallel to the present Pacific subduction zone. We interpret this anomaly to be a relict of the subducted Okhotsk plate, as suggested by Gorbatov et al. (2000). The lithosphere of the northern part is slightly faster than the other parts in the Sea of Japan, consistent with the result of a recent study by Yoshizawa et al. (2010).

The azimuthal anisotropy estimated from the phase velocity of the fundamental mode Rayleigh waves revealed that the direction of anisotropic fast axis is oriented nearly parallel to adjacent trenches, reflecting strong influence of the presence of a subducting slab on the current mantle flow. The anisotropy beneath the marginal seas seems to be weak, where the present-day tectonic activity is less than the neighbouring subduction zones.

\section{Acknowledgements}

We are grateful to the staff of the IRIS Data Management Center, the broadband seismic network in Far Eastern Russia, the Institute of Seismology and Volcanology of Hokkaido University and the Data Center of IFREE/JAMSTEC for providing us with data. We wish to thank D. Zhao and an anonymous reviewer for 
445

their helpful and constructive reviews. The first author (EB) was supported during the main period of this study by the Research Fellowship from the Japan Society of Promotion of Science. This study was partly supported by a Grant-in-Aid for Scientific Research (No. 16075201, 17740283) from the Ministry of Education, Culture, Sports, Science and Technology of Japan. The GMT software package was used to plot the figures in this paper. 
Anderson, M. L., Zandt, G., Triep, E., Fouch, M., Beck, S, 2004. Anisotropy and mantle flow in the Chile-Argentina subduction zone from shear wave splitting analysis. Geophys. Res. Lett. 31, doi:10.1029/2004GL020906.

Ando, M., 1975. Source mechanisms and tectonic significance of historical earthquakes along the nankai trough, Japan. Techtonophys. 27, 2, 119-140.

Backus, G.E., 1965. Possible forms of seismic anisotropy of the uppermost mantle under oceans. J. Geophys. Res. 70, 14, 3429-3439.

Bird, P., 2003. An updated digital model of plate boundaries. Geochem. Geophys. Geopsys. 4(3), 1027, doi:10.1029/2001GC000252.

Cara, M., Lévêque, J.J., 1987. Waveform inversion using secondary observables. Geophys. Res. Lett. 14, 10461049.

Castle, J. C., Creager, K. C., 1998. NW Pacific slab rheology, the seismicity cutoff, and the olivine to spinel phase change. Earth Planets Space 50, 977985.

Dahlen, F. A., Tromp, J., 1998. Theoretical Global Seismology, Princeton Univ. Press, Princeton, N. J.

DeMets, C., 1992. Oblique convergence and deformation along the Kuril and Japan trenches. J. Geophys. Res. 97, 17615-17626.

DeMets, C., Gordon R. G., Argus, D. F., Stein, S., 1990. Current plate motions. Geophys. J. Int. 101, 425-478.

Dziewonski, A.M., Anderson, D.L., 1981. Preliminary reference Earth model. Phys. Earth Planet. Inter. 25, 297-356. 
Ekström, G., Dziewonski, A.M., Maternovskaya, N.N., Nettles, M., 2005. Global seismicity of 2003: centroidmoment-tensor solutions for 1087 earthquakes. Phys. Earth Planet. Inter. 148, 327-351.

Fukao, Y., Widiyantoro, R.D., Ohbayashi, M., 2001. Stagnant slab in the upper and lower mantle transition zone. Rev. Geophys. 39, 291-323.

Gorbatov, A., Kostoglodov, V., Suarez, G., Gordeev, E., 1997. Seismicity and structure of the Kamchatka subduction zone. J. Geophys. Res. 102, 1788317898.

Gorbatov, Widiyantoro, S., Fukao, Y., Gordeev, E., 2000. Signature of remnant slabs in the North Pacific from P-wave tomography. Geophys. J. Int. 142, $27-$ 36.

Hasegawa, A., Horiuchi, S., Umino, N., 1994. Seismic structure of the northeastern Japan convergent margin: A synthesis. J. Geophys. Res. 99, B11, 2229522311.

Hasegawa, A., Umino, N., Takagi, A., 1978. Double-planed structure of the deep seismic zone in the northeastern Japan arc. Techtonophys. 47, 43-58.

Hasegawa, A., Zhao, D., Hori, S., Yamamoto, A., Horiuchi, S., 1991. Deep structure of the northeastern Japan arc and its relationship to seismic and volcanic activity Nature 35, 683-689.

Huang, J., Zhao, D., 2006. High-resolution mantle tomography of China and surrounding regions. J. Geophys. Res. 111, B09305, doi:10.1029/2005JB004066. 
Isse, T, Yoshizawa, K., Shiobara, H., Shinohara, M Nakahigashi, K., Mochizuki, K., Sugioka, H., Suetsugu,D., Oki, S., Kanazawa, K., Suyehiro, K., Fukao, Y., 2006. Three-dimensional shear wave structure beneath the Philippine Sea from land and ocean bottom broadband seismograms. J. Geophys. Res. 111, B06310, doi:10.1029/2005JB003750.

Katsumata, K., Wada, N., Kasahara, M., 2003. Newly imaged shape of the deep seismic zone within the subducting Pacific plate beneath the Hokkaido corner, Japan-Kurile arc-arc junction. J. Geophys. Res. 108, B12, 2565, doi:10.1029/2002JB002175.

Kennett, B.L.N., 1995. Approximations for surface-wave propagation in laterally varying media. Geophys. J. Int. 122, 2, 470-478.

Kennett, B.L.N., Yoshizawa, K., 2002. A reappraisal of regional surface wave tomography. Geophys. J. Int. 150, 1, 37-44.

Kimura, G., 1994. The latest Cretaceous - early Paleogene rapid growth of accretionary complex and exhumation of high pressure series metamorphic rocks in northwestern Pacific margin. J. Geophys. Res. 99, 22147-22164.

Kneller, E.A., van Keken, P.E., 2007. Trench-parallel flow and seismic anisotropy in the Mariana and Andean subduction systems. Nature 450, doi:10.1038/nature06429.

Lancaster, P., Salkauskas, K., 1986. Curve and Surface Fitting. Academic, San Diego, Calif.

Lebedev, S., Nolet, G., 2003. Upper mantle beneath Southeast Asia from S velocity tomography. J. Geophys. Res. 108, B1, 2048, doi:10.1029/2000JB000073. 
Lei, J., Zhao, D., 2005. P-wave tomography and origin of the Changbai intraplate volcano in Northeast Asia. Techtonophys. 397, 281-295.

Li H.-Y., Liu, F.-T., Sun, R.-M., Zheng, Y.-J., Peng, Y.-J., Huang, Z.-X., 2001. Crust and upper mantle structure in east China and sea areas. Acta Seismologica Sinica, 14, 5, 503-511.

Miller, M.S., Kennett, B.L.N., Toy, V.G., 2006. Spatial and temporal evolution of the subducting Pacific plate structure along the western Pacific margin. J. Geophys. Res. 111, B02401, doi:10.1029/2005JB003705.

Mishra, O.P., Zhao, D., Umino, N., Hasegawa, A., 2003. Tomography of northeast Japan forearc and its implications for interplate seismic coupling. Geophys. Res. Lett. 30, 16, 1850, doi:10.1029/2003GL017736.

Miyamachi, H., Ichiyanagi, M., Maeda, T., Yamaguchi, T., Takada, M., Takahashi, H., Kasahara, M., Hirano, S., Sen Rak Se, Mikhaylov V., Mikrukoba, O., Levin, Yu., Kim Chun Ung, Vasilenko, N., Shestakov, N., Gerasimeko, M., Bormotov V., Luneva M., Gunbina L., 2009. Construction of the broadband seismic network in Far Eastern Russia for imaging the stagnant slab. Geophysical Bulletin of Hokkaido University 72, 37-49.

Nakajima, J., Hasegawa, A., 2004. Shear-wave polarization anisotropy and subduction-induced flow in the mantle wedge of northeastern Japan. Earth Planet. Sci. Lett. 225, 365-377.

Nataf, H.-C., and Y. Ricard, 1996. 3SMAC: An a priori tomographic model of the upper mantle based on geophysical modeling. Phys. Earth Planet. Inter. 95, 101122. 
Nataf, H.C., Nakanishi, I., Anderson, D.L., 1986. Measurements of numerous useful discussions. We also wish to thank the members of RSES mantle wave velocities and inversion for lateral heterogeneities and at the Australian National University for their invaluable support for anisotropy: 3. Inversion. J. Geophys. Res. 91, 72617307.

Nishimura, C. E., Forsyth, D., W., 1989. The anisotropic structure of the upper mantle in the Pacific. Geophys. J. 96, 203229.

Parfenov, L.M., Natal'in, B.A., 1985. Mesozoic accretion and collision tectonics of northeastern Asia, in Tectonostratigraphic Terranes of the Circum-Pacific Region, pp. 363373, ed. Howell, D.G., Circum-Pacific Council, Houston, TX.

Park, J., Levin, V., Lees, J., Brandon, M.T., Peyton, V., Gordeev, E., Ozerov, A., 2002. Seismic anisotropy and mantle flow in the Kamchatka-Aleutian corner, In: S. Stein (ed), Plate Boundary Zones, Geophysical Monograph, American Geophysical Union, Washington DC.

Priestley, K., Debayle, E., McKenzie, D., Pilidou, S., 2006. Upper mantle structure of eastern Asia from multimode surface waveform tomography. J. Geophys. Res. 111, B10304, doi:10.1029/2005JB004082.

Ritzwoller, M.H., Levshin, A.L., 1998. Eurasian surface wave tomography: Group velocities. J. Geophys. Res. 103, B3, 4839-4878.

Sambridge, M., 1999. Geophysical inversion with a Neighbourhood algorithm I. Searching a parameter space. Geophys. J. Int. 138, 479494.

Seno, T., 1999. Syntheses of the regional stress fields of the Japanese islands. The Island Arc 8, 1, 66-79. 
Seno, T., Sakurai, T., Stein, S., 1996. Can the Okhotsk plate be discriminated from the North American plate? J. Geophys. Res. 101, 11305-11315.

Seno, T., Stein, S., Gripp, A.E., 1993. A model for the motion of the Philippine Sea consistent with NUVEL-1. J. Geophys. Res. 98, 17941-17948.

Shelly, D.R., Beroza, G.C., Zhang, H., Thurber, C.H., Ide, S., 2006. Highresolution subduction zone seismicity and velocity structure beneath Ibaraki Prefecture, Japan. J. Geophys. Res. 111, B06311, doi:10.1029/2005JB004081

Smith, M. L., Dahlen, F.A., 1973. The Azimuthal Dependence of Love and Rayleigh Wave Propagation in a Slightly Anisotropic Medium. J. Geophys. Res. $78,17,33213333$.

Sugimura, A., 1972. Plate boundaries near Japan. Kagaku (Sci.), 42, 192-202 (in Japanese).

Taira, A., 2001. Tectonic evolution of the Japanese islands arc system. Annu. Rev. Planet. Sci. 29, 109-134.

Takeuchi, H., and M. Saito (1972), Seismic surface waves, in Seismology: Surface Waves and Free Oscillations, Methods Comput. Phys., vol. 11, edited by B. A. Bolt, pp. 217 295, Academic, San Diego, Calif.

Tarantola, A., Valette, B., 1982. Generalized nonlinear inverse problems solved using the least-squares criterion, Rev. Geophys. 20, 219232.

Takezoe, H., Yoshizawa, K., Yomogida, K., 2005. Rayleigh wave phase velocity distribution in the Japanese islands estimated from array analysis, Proc. Symp. Stagnant Slab Project, 70-72. (in Japanese) 
van der Hilst, R. D., Engdahl, E. R., Spakman, W., Nolet, G., 1991, Tomographic imaging of subducted lithosphere below northwest Pacific island arcs. Nature $353,3743$.

van der Hilst, R. D., Widiyantoro, S., Creager, K.C., McSweeney, T. J., 1998. Deep subduction and aspherical variations in P-wavespeed at the base of Earths mantle, Geodynamics, AGU 28520.

van Heijst, H.J., Woodhouse, J., 1999. Global high resolution phase velocity distributions of overtone and fundamental-mode surface waves determined by mode branch stripping. Geophys. J. Int. 137, 601-620.

Verzhbitsky, E.V., Berlin, Yu.M., Kononov, M.V., Marina, M.M., 2006. Estimates of the temperatures of hydrocarbon generation in the region of the Sea of Okhotsk. Oceanology 46, 4, 572-583.

Verzhbitsky, E.V., Kononov, M.V., 2006. Geodynamic evolution of the lithosphere of the Sea of Okhotsk region from geophysical data. Izvestiya Physics of the Solid Earth 42, 6, 490-501.

Wang, Z., Dahlen, F.A., 1995. Spherical-spline parameterization of threedimensional Earth models. Geophys. Res. Lett. 22, 30993102.

Wang, K., Zhao, D., 2005. Seismic imaging of the entire arc of Tohoku and Hokkaido in Japan using P-wave, S-wave and sP depth-phase data. Phys. Earth Planet. Inter. 152, 3, 144-162.

Wang, J., Zhao, D., 2008. P-wave anisotropic tomography beneath Northeast Japan Phys. Earth Planet. Inter. 170, 115-133. 
Wang, J., Zhao, D., 2009. P-wave anisotropic tomography of the crust and upper mantle under Hokkaido, Japan. Tectonophysics 469, 137-149.

Wei, D., Seno, T., 1998. Determination of the Amurian plate motion, in Mantle Dynamics and Plate Interactions in East Asia, Geodyn. Ser. 27, edited by M. F. J. Flower et al., 419 p., AGU, Washington, DC.

Widiyantoro, S., Kennett, B.L.N., van der Hilst, R.D., 1999. Seismic tomography with $\mathrm{P}$ and $\mathrm{S}$ data reveals lateral variations in the rigidity of deep slabs. Earth Planet. Sci. Lett. 173, 91100.

Yoshizawa, K., Ekström, G., 2009. Automated multi-mode phase speed measurements for high-resolution regional-scale tomography: Application to North America. Geophys. J. Int. submitted.

Yoshizawa, K., Kennett, B.L.N., 2002a. Non-linear waveform inversion for surface waves with a neighbourhood algorithm-application to multimode dispersion measurements. Geophys. J. Int. 149, 1, 118-133.

Yoshizawa, K., Kennett, B.L.N., 2002b. Determination of the influence zone for surface wave paths. Geophys. J. Int. 149, 440453.

Yoshizawa, K., Kennett, B.L.N., 2004. Multimode surface wave tomography for the Australian region using a three-stage approach incorporating finite frequency effects. J. Geophys. Res. 109, B02310, doi:10.1029/2002JB002254.

Yoshizawa, K., Miyake, K., and Yomogida, K., 2010. 3-D upper mantle structure beneath Japan and its surround region from inter-station dispersion measurements of surface waves, Phys. Earth Planet. Inter. doi:10.1016/j.pepi.2010.02.012. 
Zhao, D., 2001. New advances of seismic tomography and its applications to subduction zones and earthquake fault zone: A review. The Island Arc 10, 68-84.

Zhao, D., 2004. Global tomographic images of mantle plumes and subducting slabs: insight into deep Earth dynamics. Phys. Earth Planet. Inter. 146, 334.

Zhao, D., 2009. Multiscale seismic tomography and mantle dynamics. Gondwana Research 15, 297323.

Zhao, D., Hasegawa, A., Kanamori, H., 1994. Deep structure of Japan subduction zone as derived from local, regional, and teleseismic events. J. Geophys. Res. 99, 22313-22329.

Zhao, D., Wang, Z., Umino, N., Hasegawa, A., 2009. Mapping the mantle wedge and intraplate thrust zone of the northeast Japan arc. Tectonophysics 467, 89106.

Zonenshain, L.P., Savostin, L.A., 1981. Geodynamics of the Baikal rift zone and plate tectonics of Asia. Techtonophys. 76, 1-45. 


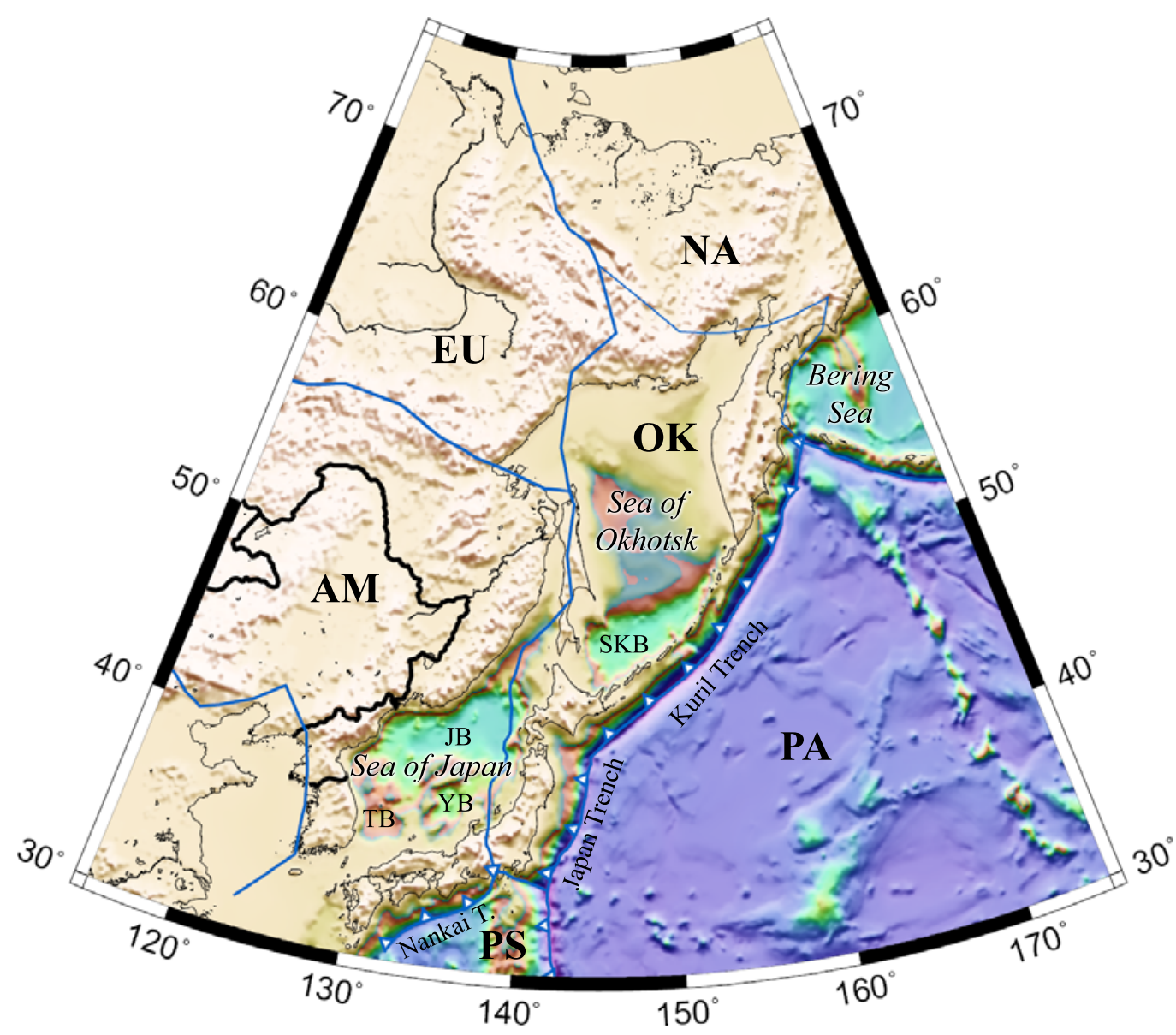

Figure 1: Tectonic map of the northeastern Eurasian region. Plate boundaries are indicated by solid lines according to PB2002 model by Bird (2003). PA: Pacific plate, PS: Philippine Sea plate, OK: Okhotsk plate, AM: Amur plate, NA: North American plate, EU: Eurasian plate. JB: Japan basin, YB: Yamato basin, TB: Tsushima basin, SKB: South Kuril basin. 


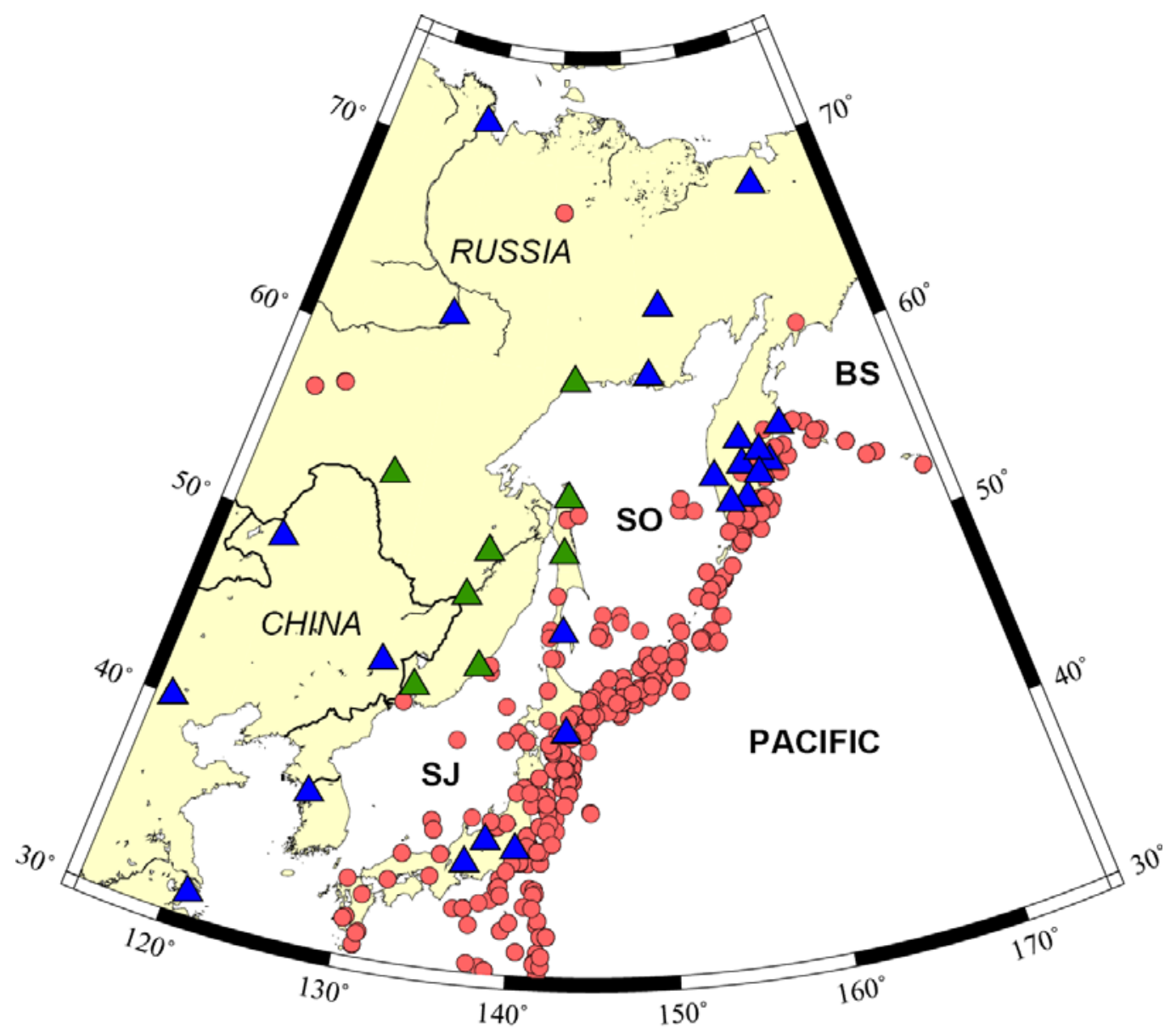

- Events

$\triangle$ Broadband seismic network in Far Eastern Russia

- IRIS stations

Figure 2: Events and station distributions of this study. The data set is composed of threecomponent seismograms recorded by 25 IRIS stations (blue triangles) and 8 stations of the broadband seismic network in Far Eastern Russia (green triangles) from 305 events (red circles). SJ: Sea of Japan, SO: Sea of Okhotsk, BS: Bering Sea. 
(a) WAVEFORM FIT

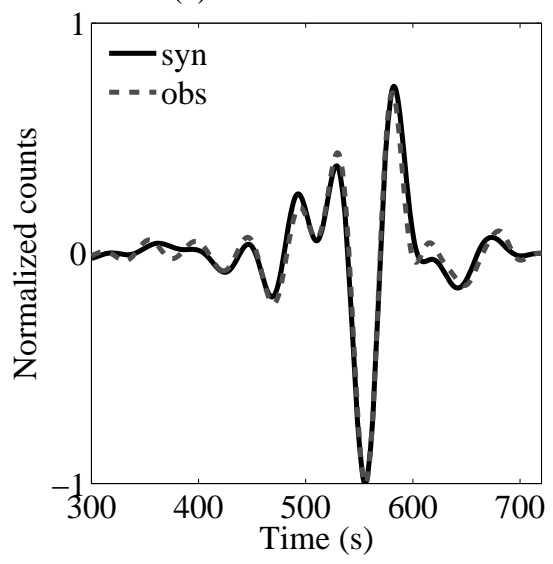

(c) PHASE VELOCITY

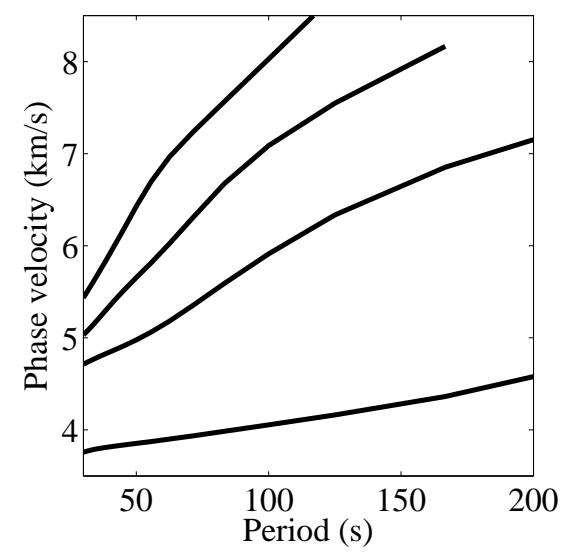

(b) S MODEL

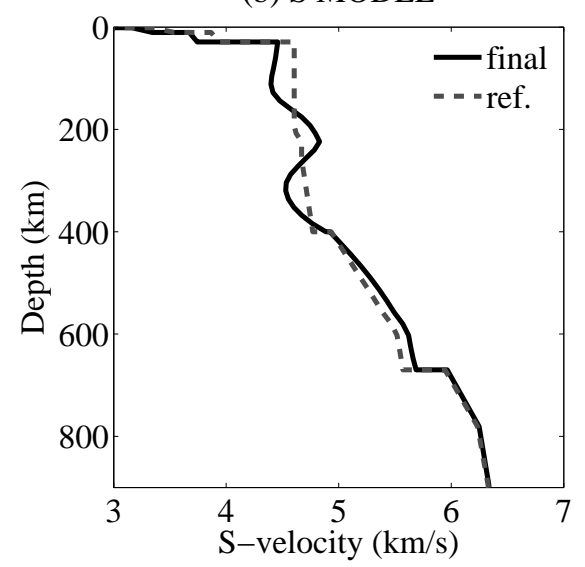

(d) RELIABILITY

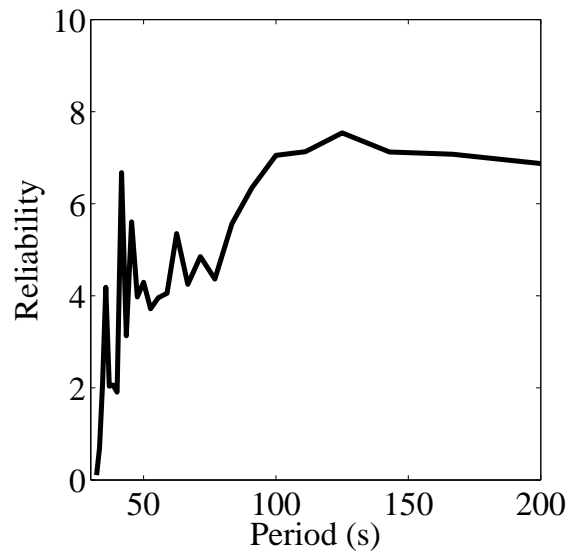

Figure 3: An example of NA waveform inversion for Rayleigh wave at the station HIA: (a) waveform fit; (b) path-average 1D profile; (c) multimode phase velocity dispersion curves estimated from this 1D model; (d) reliability parameter. 


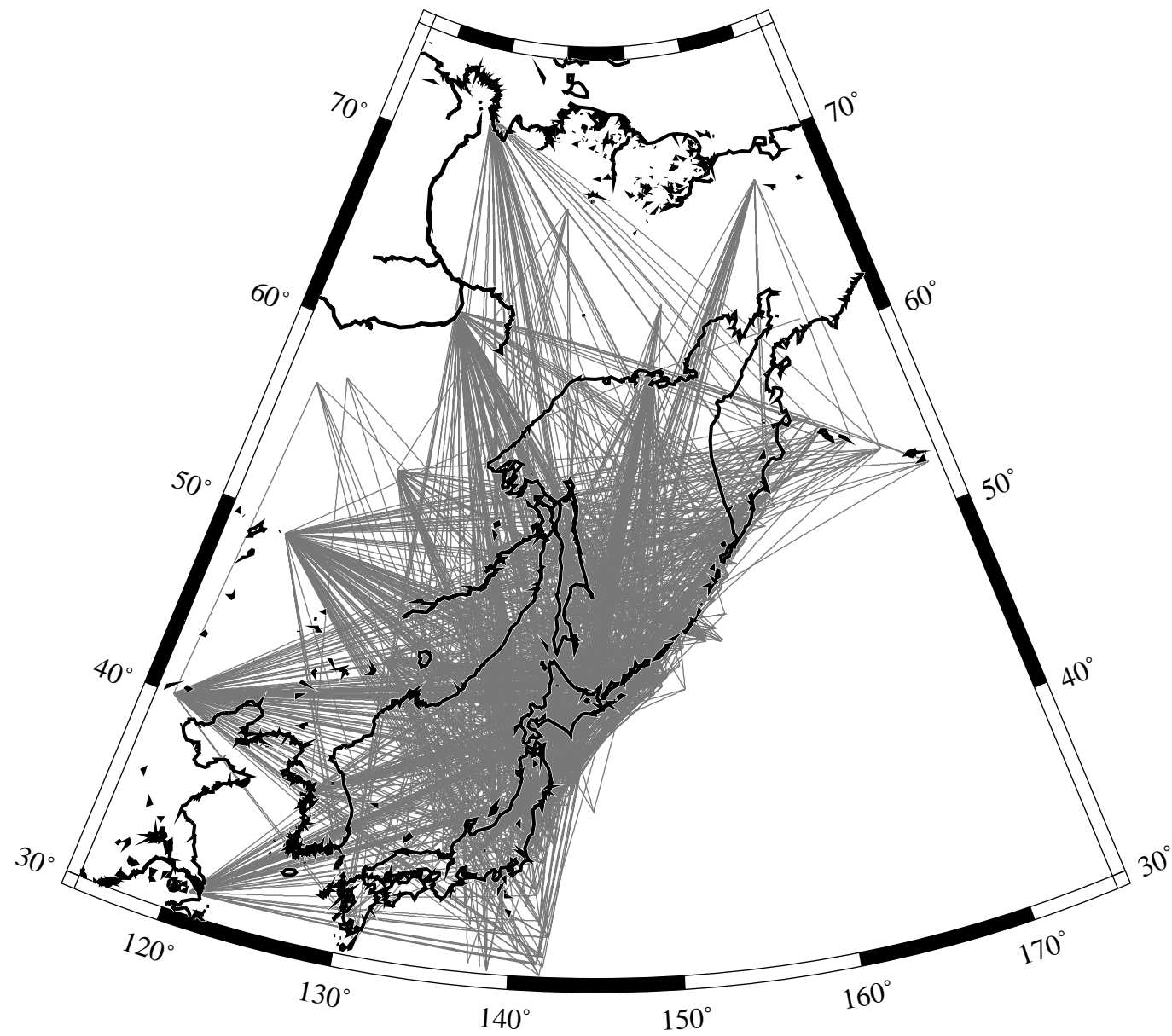

Figure 4: Distribution of the total number of 1129 paths used to constrain phase velocity models. The number of used paths for each phase velocity model depends on period and mode, varying from 980 to 1099 with all the paths displayed in this Figure. 
(a)

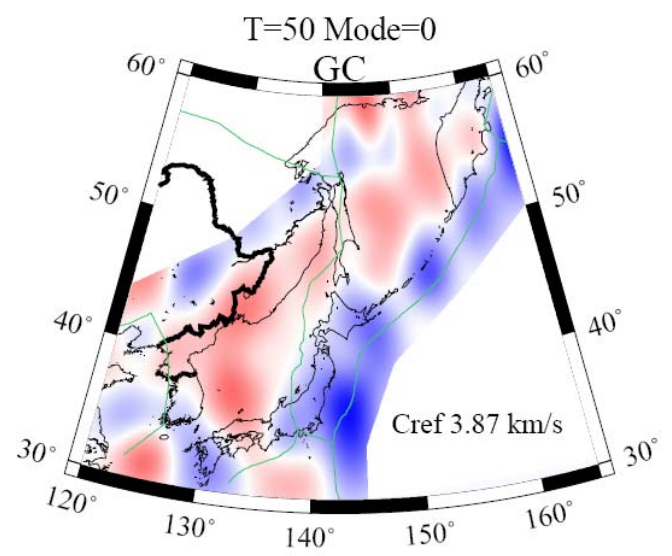

(b)

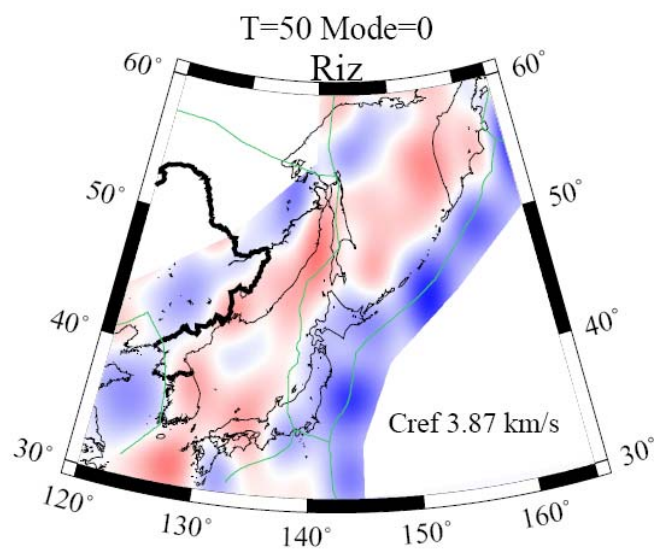

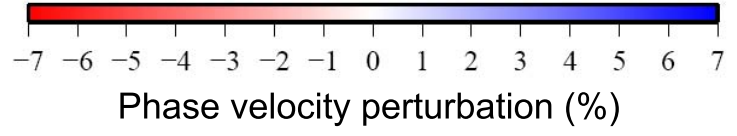

Figure 5: Phase velocity perturbation maps of the fundamental mode Rayleigh wave at $50 \mathrm{~s}$ period obtained for (a) the GC model and (b) Riz model. The reference phase velocity is $3.87 \mathrm{~km} / \mathrm{s}$. 


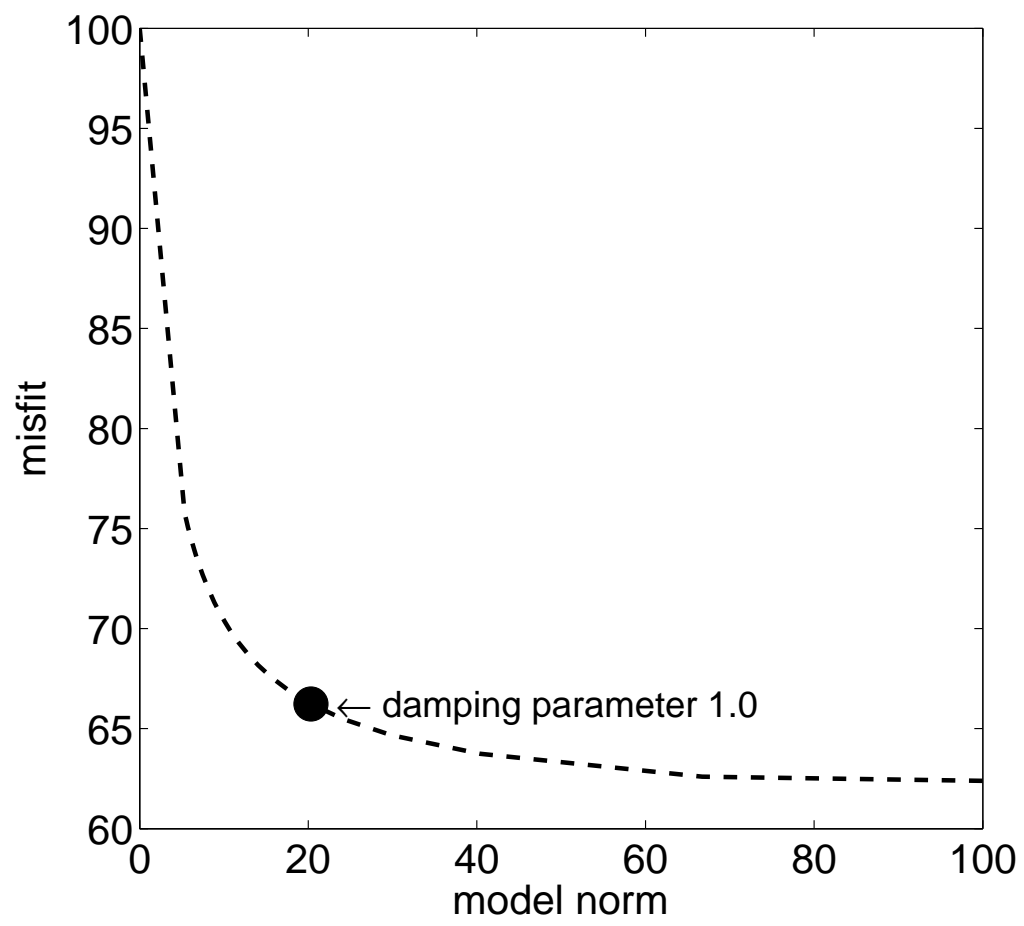

Figure 6: Trade-off curve between the misfit and the model norm for different damping parameters in the Riz model at period of $100 \mathrm{~s}$. We chose the damping parameter $\lambda=1.0$ as the most appropriate for this inversion. 


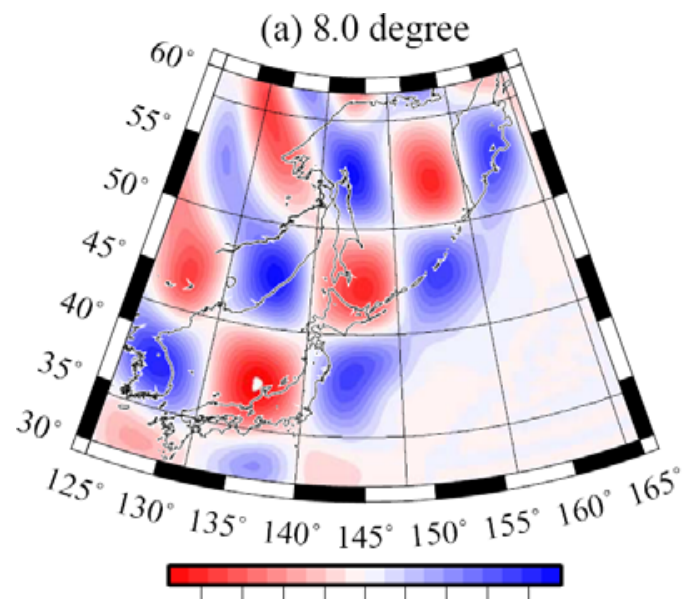

$-4-3-2-1 \quad 0 \quad 1 \quad 2 \quad 3 \quad 4$

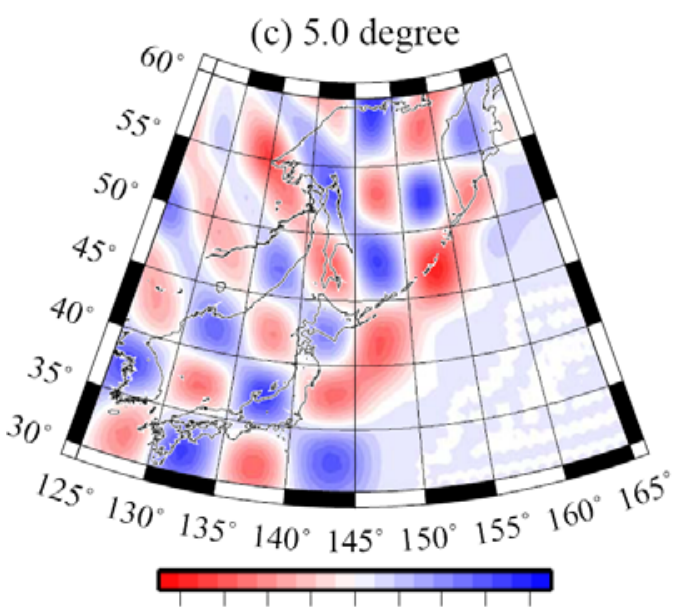

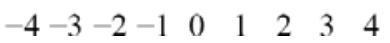

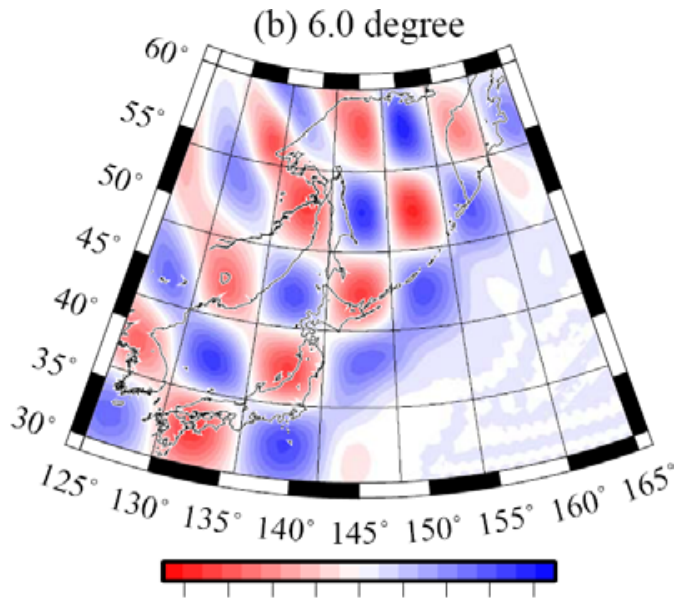

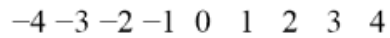

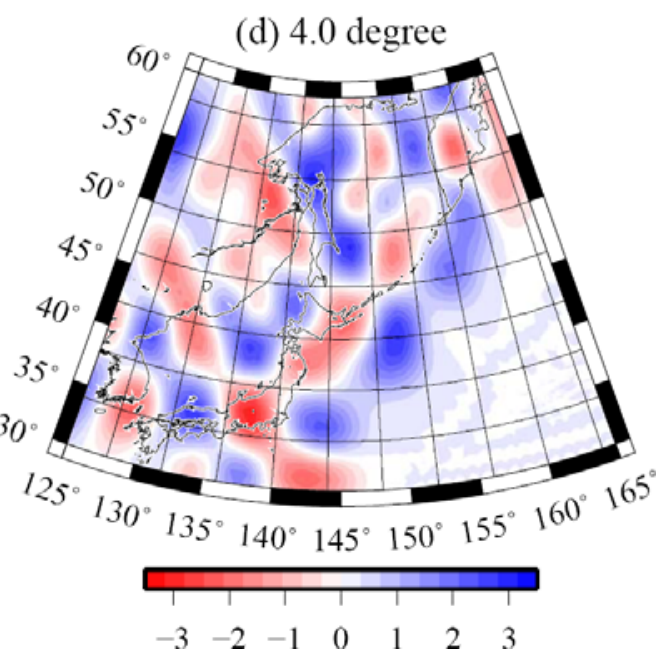

Figure 7: Results of checkerboard resolution tests at period of $50 \mathrm{~s}$ for different cell sizes: 8, 6, 5 and 4 degrees. 

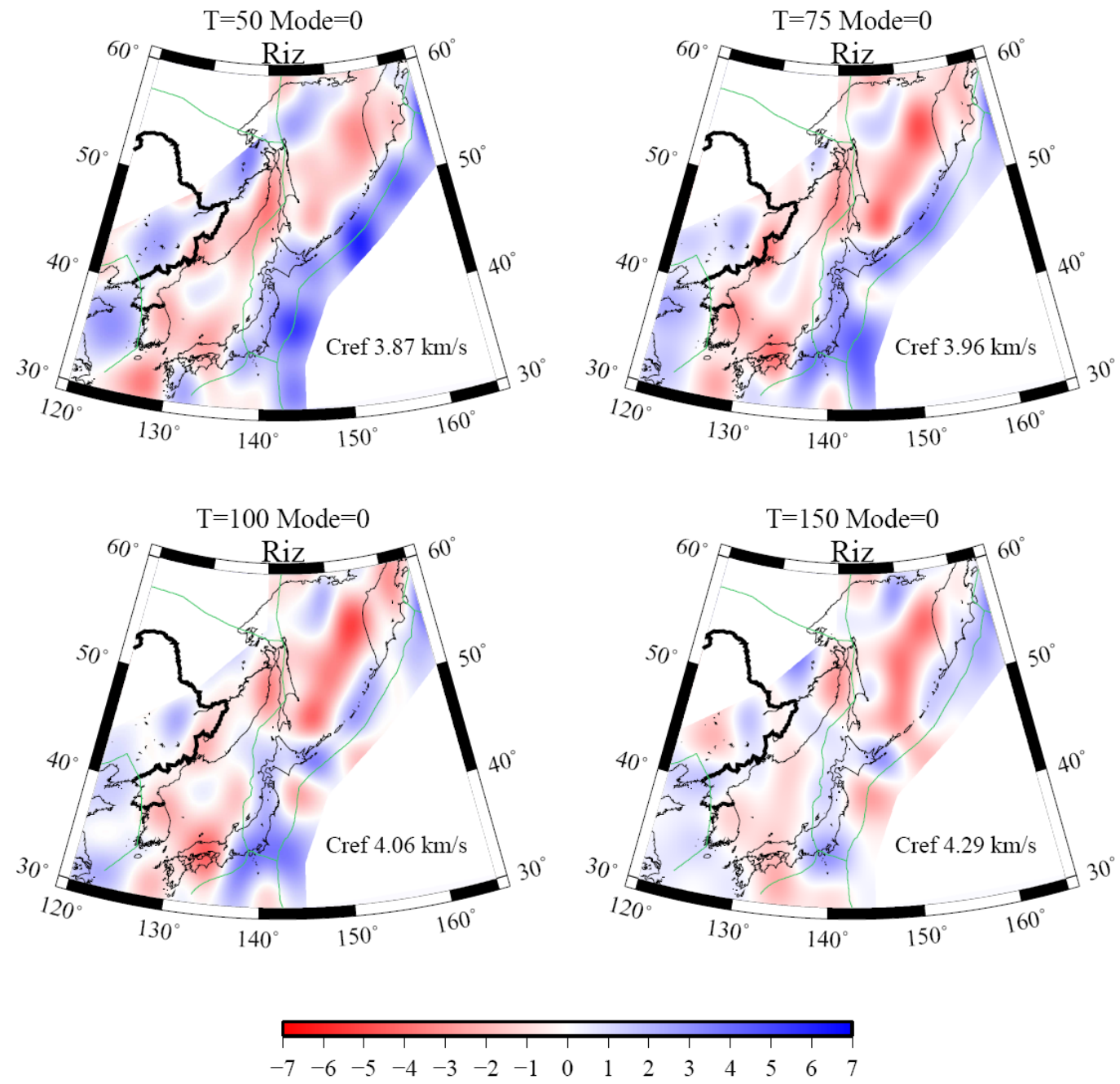

Phase velocity perturbation (\%)

Figure 8: Phase velocity maps of the fundamental mode Rayleigh waves obtained with 3 degree grid. 


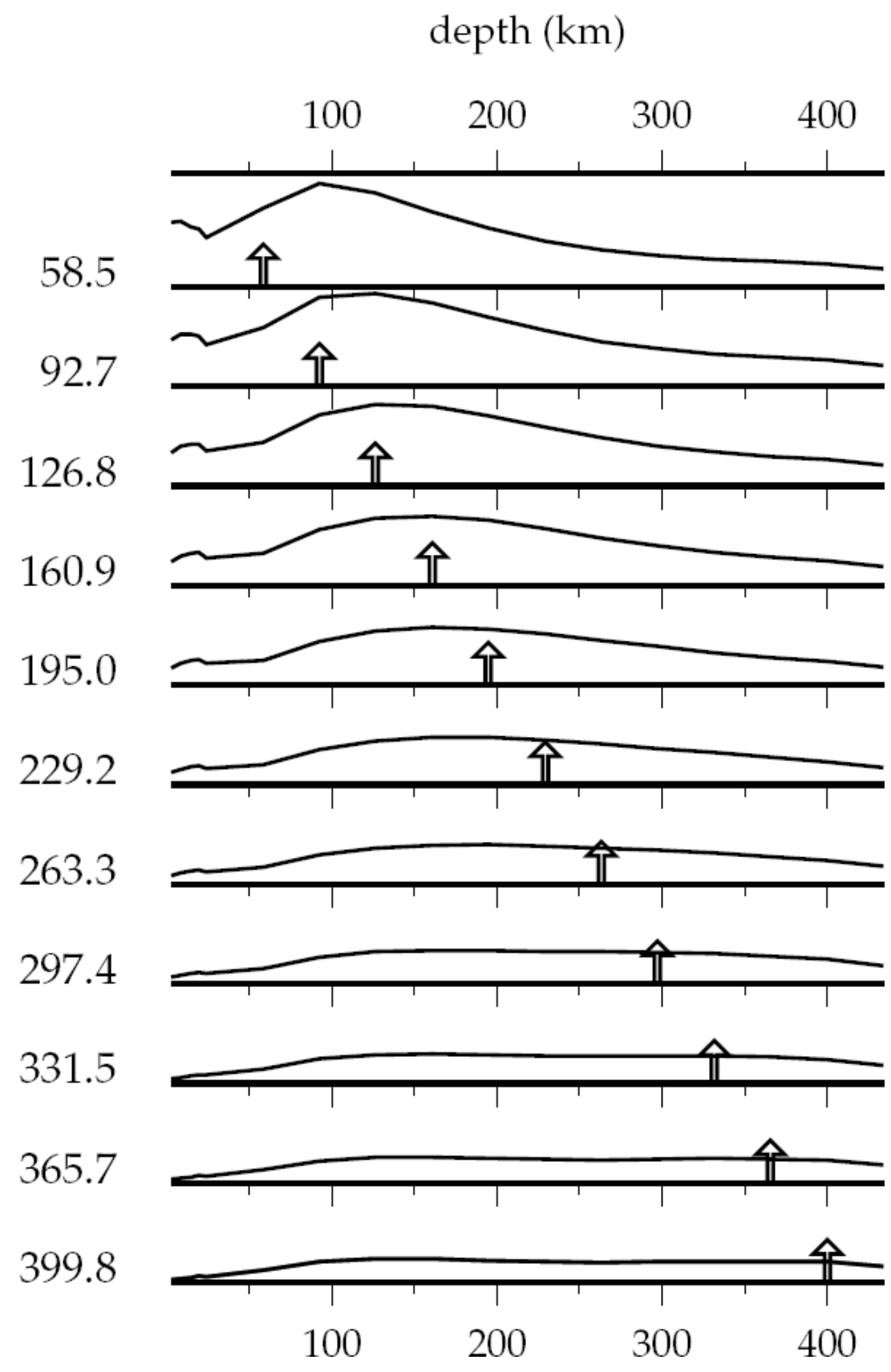

Figure 9: Resolution kernels for S-wave velocity profile beneath the location at $\left(35^{\circ} \mathrm{N}, 140^{\circ} \mathrm{E}\right)$. An ideal vertical resolution would show a delta-like peak around each depth marked by arrows. In this example, the structure is relatively well resolved down to $200-250 \mathrm{~km}$ in depth, mainly due to the fundamental mode sensitivity. 

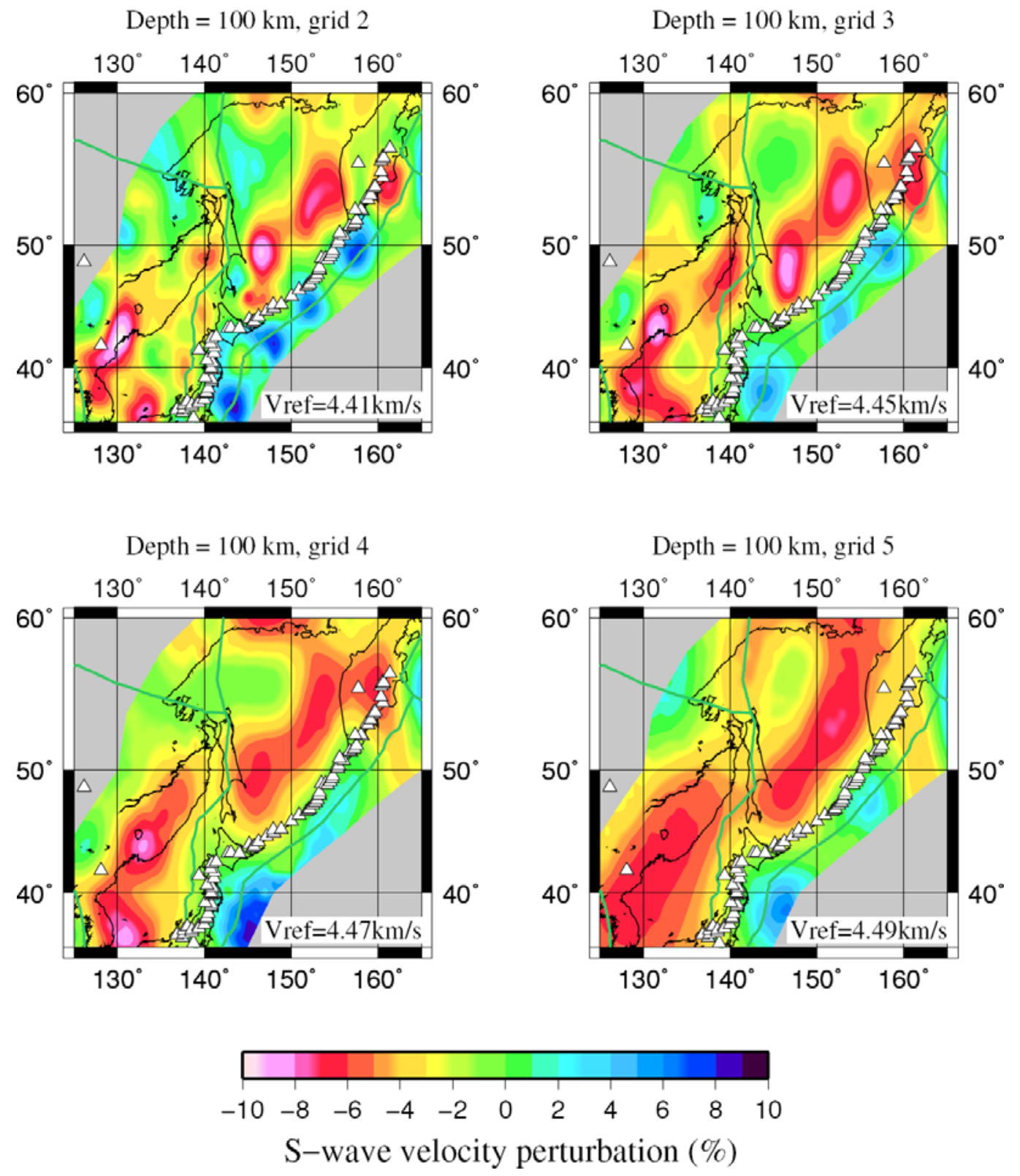

Figure 10: Comparison of S-wave velocity perturbation maps at $100 \mathrm{~km}$ depth with different grids: (a) 2, (b) 3, (c) 4 and (d) 5 degrees. The distribution of S-wave velocity in the region is plotted relative to the average S-wave velocity $V_{\text {ref }}$ for each map. White triangles denote active volcanoes. 
Depth $=50 \mathrm{~km}$, grid 3

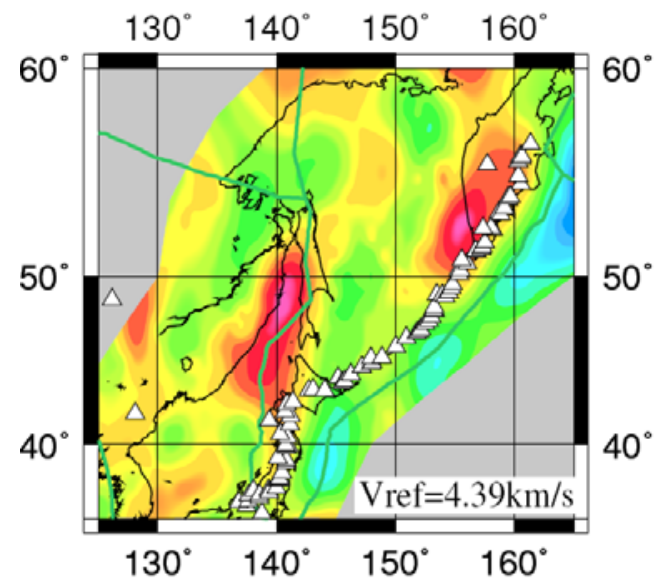

Depth $=150 \mathrm{~km}$, grid 3

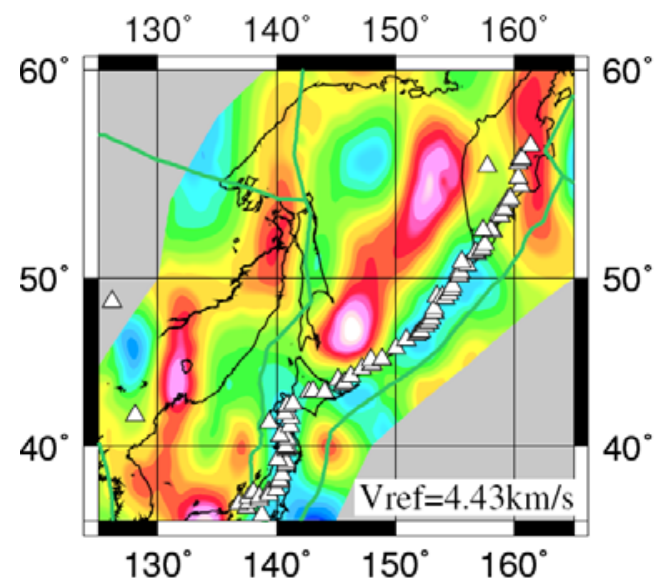

Depth $=100 \mathrm{~km}$, grid 3

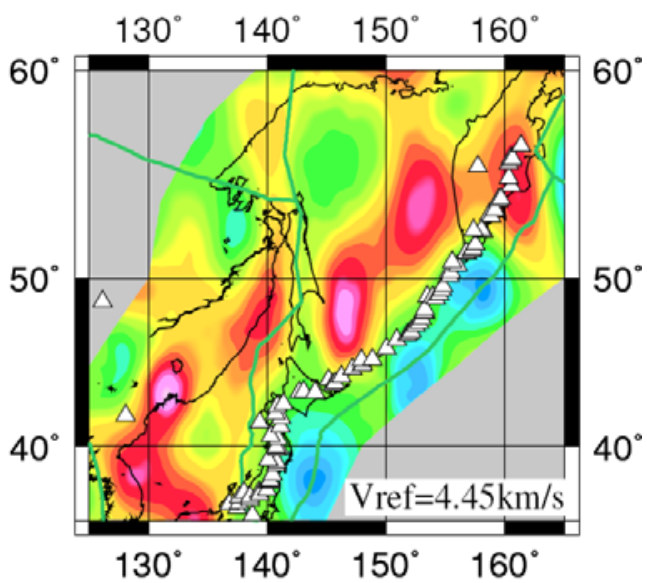

Depth $=200 \mathrm{~km}$, grid 3

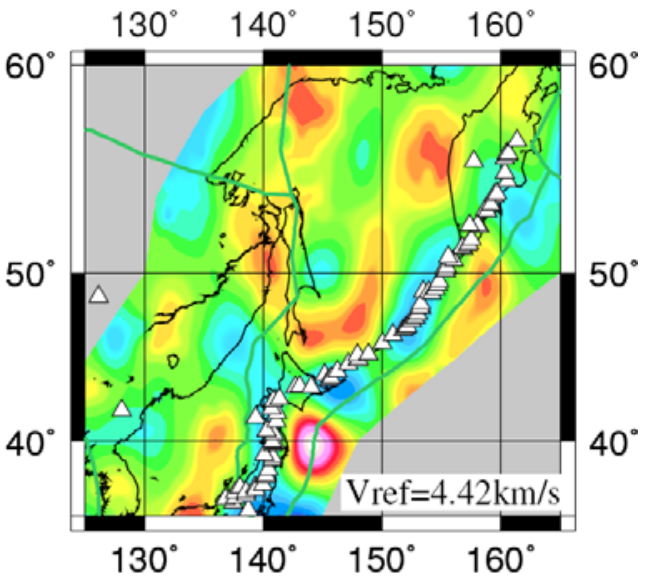

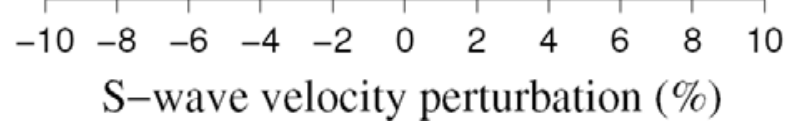

Figure 11: S-wave velocity perturbation maps for grids of 3 degrees from 50 to $200 \mathrm{~km}$ depth. The distribution of S-wave velocity in the region is plotted relative to the average S-wave velocity $V_{r e f}$ for each map. White triangles denote active volcanoes. 

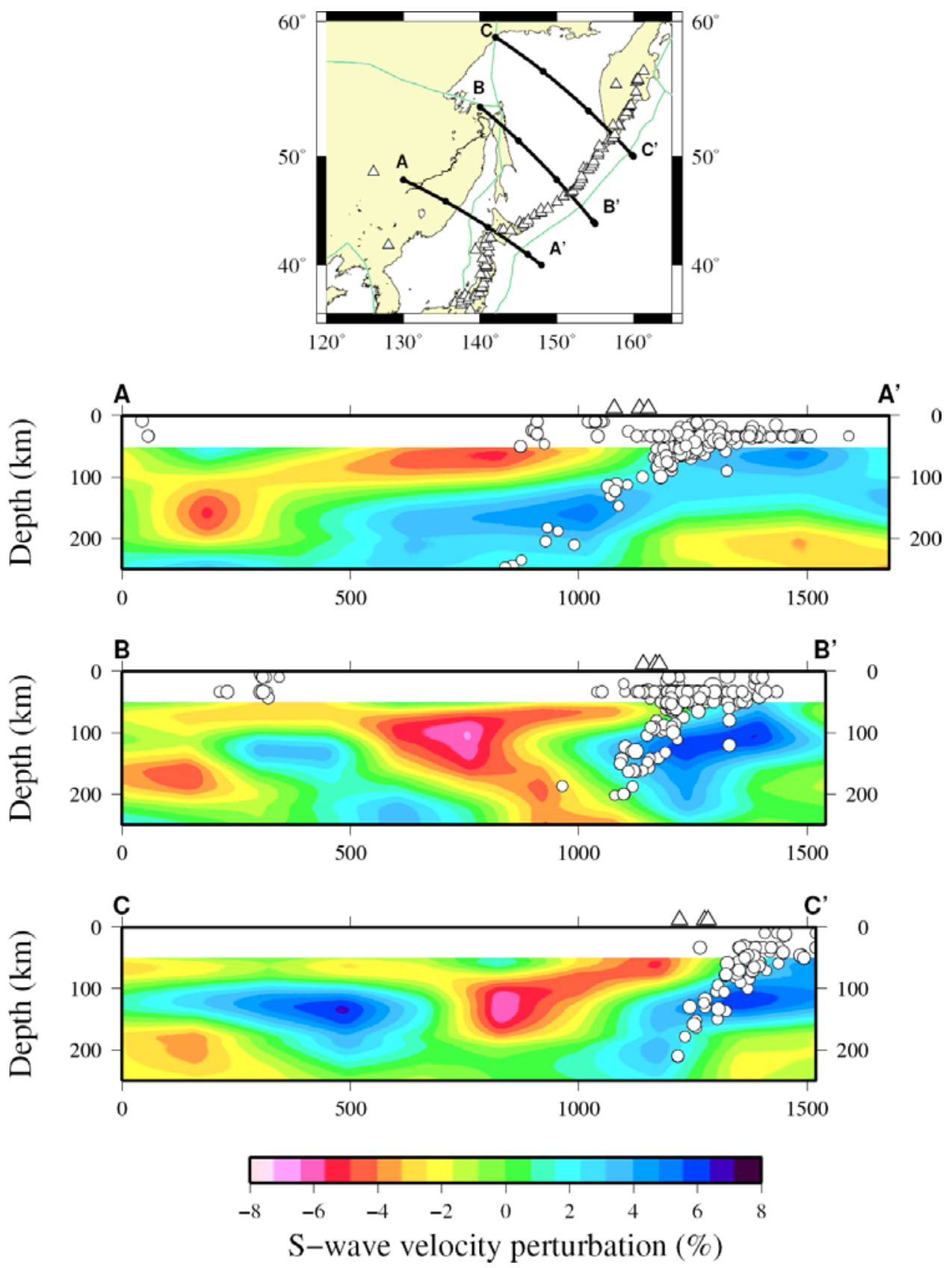

Figure 12: S-wave velocity cross sections along three profiles AA', BB' and CC'. The orientation of the profiles is perpendicular to each subduction trench axis. The distribution of S-wave velocity is plotted relative to the average S-wave velocity at each depth. White triangles denote active volcanoes. White circles show earthquakes that occurred along each profile. 
(a) 8.0 degree: Input

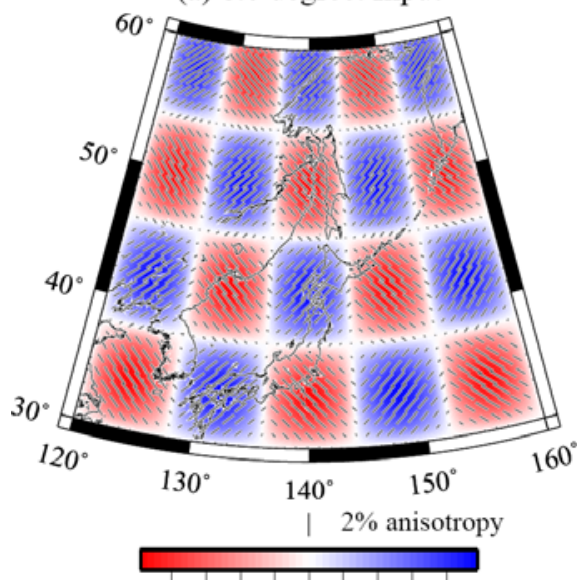

$\begin{array}{lllllllll}-4 & -3 & -2 & -1 & 0 & 1 & 2 & 3 & 4\end{array}$

(b) 10.0 degree: Input

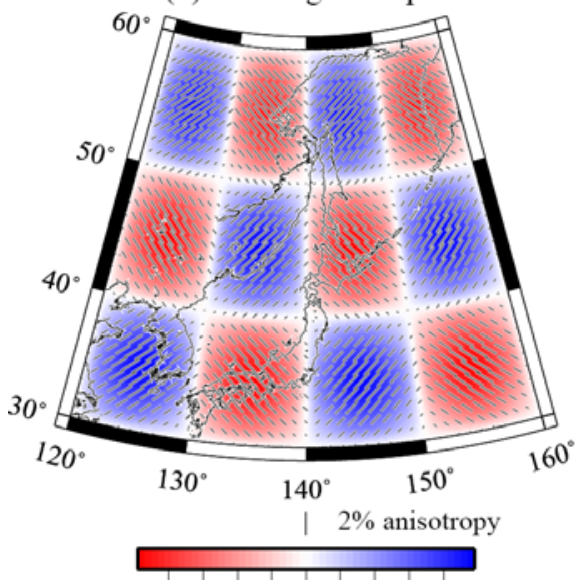

$\begin{array}{lllllllll}-4 & -3 & -2 & -1 & 0 & 1 & 2 & 3 & 4\end{array}$ (c) 8.0 degree: Output

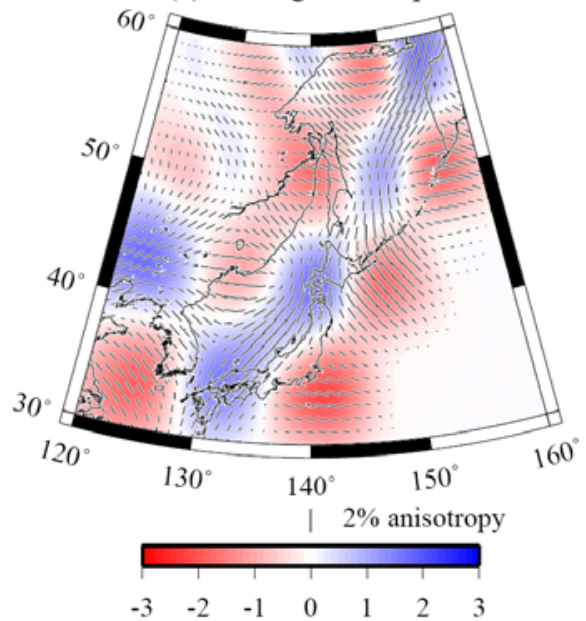

(d) 10.0 degree: Output

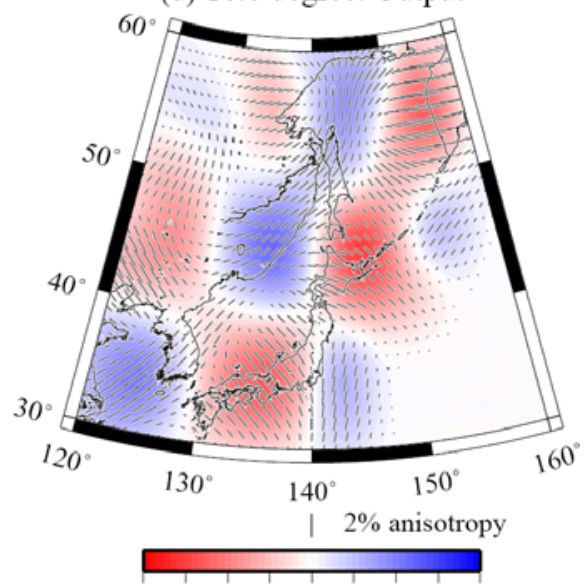

$\begin{array}{lllllllll}-4 & -3 & -2 & -1 & 0 & 1 & 2 & 3 & 4\end{array}$

Figure 13: Results of checkerboard resolution test for azimuthal anisotropy at period of $50 \mathrm{~s}$ for 8 and 10-degree cellular patterns. (a,b) Input models for phase velocity with anomalies of \pm 4.8-percent amplitude and for the anisotropic term with $2 \%$ anisotropy at maximum. The fastest direction at each location is represented by the orientation of each bar, and the strength by its length. (c,d) Recovered isotropic heterogeneity and azimuthal anisotropy. 

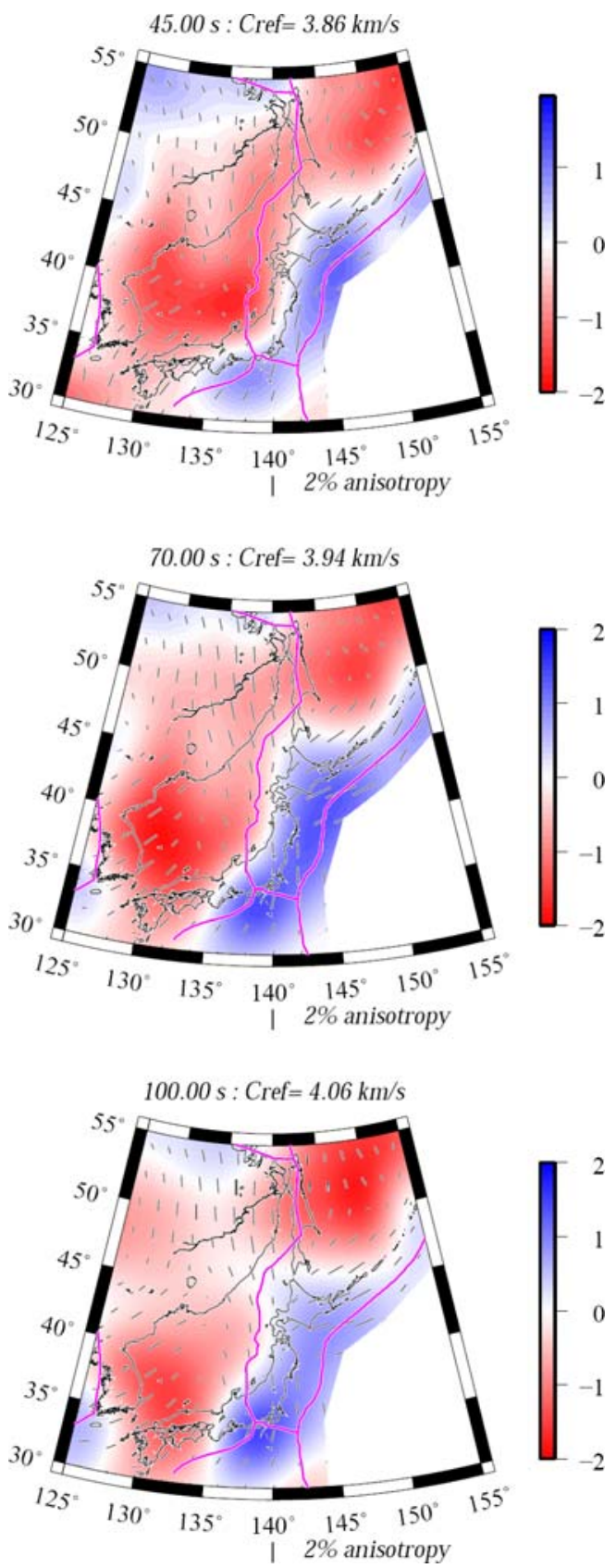

Figure 14: Phase velocity maps of the fundamental mode Rayleigh wave with anisotropic term at (a) $45 \mathrm{~s}$, (b) $70 \mathrm{~s}$ and (c) $100 \mathrm{~s}$. The fastest direction at each location is represented by the orientation of each bar, and the strength by its length. 